\title{
ANTIBACTERIAL AND ENZYME INHIBITION SCREENING OF SOME NEW ACETAMIDE AND AZOMETHINE DERIVATIVES
}

\author{
SHAHID RASOOL ${ }^{a}$, AZIZ-UR-REHMAN ${ }^{a}, *$, MUHAMMAD ATHAR ABBASI ${ }^{a}$, SABAHAT ZAHRA SIDDIQUI ${ }^{a}$, SYED \\ ADNAN ALI SHAH ${ }^{b, c}$, IRSHAD AHMAD ${ }^{c}$ AND SAIRA AFZAL ${ }^{c}$
}

\author{
${ }^{a}$ Department of Chemistry, Government College University, Lahore-54000, Pakistan. \\ ${ }^{b}$ Catta-ur-Rahman Institute for Natural Products Discovery (Aurins), Universiti Teknologi Mara, Puncak Alam Campus 42300 Bandar \\ Puncak Alam Selangor D. E. Malaysia \\ 'Department of Pharmacy, The Islamia University of Bahawalpur, Bahawalpur-63100, Pakistan.
}

\begin{abstract}
The synthesis of poly-functional moieties as one unit has been under consideration by the synthetic chemists to search out new potent molecules. 2-Chlorobenzoic acid (1) was converted to 5-(2-chlorophenyl)-1,3,4-Oxadiazol-2-thiol (4) through a series of steps. This nucleophile was attached with different electrophiles, prepared by the reaction of aryl/alkyl amines with 2-bromoacetylbromide, in NaH/DMF to synthesize $N$-substituted-2-((5-(2-chlorophenyl)-1,3,4-Oxadiazol-2yl)sulfanyl)acetamide, 7a-f. The molecule 4 was stepped to ethyl ester and carbohydrazide. The carbohydrazide was made to react with aryl carboxaldehydes in methanol to synthesize $N$ '-substituted-2-(5-(2-chlorophenyl)-1,3,4-Oxadiazol-2-ylthio)acetohydrazide, 11a-i. The structures of all the molecules were corroborated through IR, ${ }^{1} \mathrm{H}-\mathrm{NMR}$ and EI-MS spectral data. Both the series were screened for antibacterial and enzyme inhibition activity.
\end{abstract}

Keywords: 1,3,4-Oxadiazole, 2-chlorobenzoic acid, acetamides, antibacterial activity, enzyme inhibition activity.

\section{INTRODUCTION}

Now-a-days, the synthetic chemists are interested to introducenew molecules bearing multiple functionalities in order to boost up their pharmacological activities. The molecules bearing heterocyclic 1,3,4-Oxadiazole ring $^{1-4}$, acetamoyl moiety ${ }^{5-9}$ and azomethine moiety ${ }^{10-13}$ have been demonstrated to exhibit a wide spectrum of pharmacological activities including anticancer, antimicrobial, antidepressant, anti-inflammatory, antioxidant, anticonvulsant and many other activities. We have introduced different molecules possessing multiple functionalities ${ }^{14-17}$ along with remarkable antibacterial and antienzymatic activities.

In continuation of our previous work, the present work was attempted to search out some new molecules with pharmacological applications including antibacterial and enzyme inhibition activity. Although some of the synthesized molecules are commercially available ${ }^{18}$ yet we are reporting here the simple way of synthesis along with their biological activity including enzyme inhibition against lipoxygenase and antibacterial against certain strains of Gram-positive and Gram-negative bacteria. The detailed SAR study of all the synthesized molecules in comparison of reported analogues has been discussed. Here two different series of compounds were synthesized and compared within/inbetween the groups for their biological activities.

\section{EXPERIMENTAL}

\subsection{General}

The synthetic grade chemicals were purchased through Alfa Aesar, Merck and Sigma-Aldrich through local suppliers along with analytical grade solvents. Thin layer chromatography (TLC) was the initial tool to verify the reaction completion and purity of compounds. It was performed on aluminum plate coated with silica gel G-25-UV ${ }_{254}$, run through a solvent system prepared by the combination of different ratios of AcOEt and $n$-Hexane and visualized under Camag UV lamp at $254 \mathrm{~nm}$. The melting points were noted by GriffinGeorge apparatus with open capillary tube and were uncorrected. The infra red (IR) spectra were recorded by Jasco-320-A spectrophotometer using $\mathrm{KBr}$ pellet method. The proton nuclear magnetic resonance $\left({ }^{1} \mathrm{H}-\mathrm{NMR}\right)$ spectra were recorded by Bruker spectrometer at 400 and $600 \mathrm{MHz}$ in deuterated chloroform $\left(\mathrm{CHCl}_{3}-d_{l}\right)$ and deuterated dimethylsulfoxide (DMSO- $\left.d_{6}\right)$, respectively. The mass (EIMS) spectra were recorded by JMS-HX-110 spectrometer.

\subsection{Synthesis of ethyl 2-chlorobenzoate (2)}

2-Chlorobenzoic acid $(\mathbf{1} ; 2 \mathrm{~g}, 0.01 \mathrm{~mol})$ was mixed with $12 \mathrm{~mL}$ ethanol in a $100 \mathrm{~mL}$ round bottom (RB) flask followed by the addition of $1.0 \mathrm{~mL}$ concentrated $\mathrm{H}_{2} \mathrm{SO}_{4}$ as catalyst and set to reflux for 4-5 hours. The maximal completion was confirmed through TLC and then the flask contents were transferred to a $250 \mathrm{~mL}$ separating funnel. $50 \mathrm{~mL}$ distilled water was introduced and basified up to $\mathrm{pH}$ of 8-10 by adding concentrated aqueous $\mathrm{Na}_{2} \mathrm{CO}_{3}$ solution. Then $30 \mathrm{~mL}$ ether was added in fractions to extract the ester. Yellow liquid;
Yield: 83\%; Molecular Formula: $\mathrm{C}_{9} \mathrm{H}_{9} \mathrm{ClO}_{2}$; Molecular Weight: $184 \mathrm{gmol}^{-1}$; IR $\left(\mathrm{KBr}, v_{\text {max }} / \mathrm{cm}^{-1}\right)$ : $3105(\mathrm{Ar} \mathrm{C}-\mathrm{H}), 1738(\mathrm{C}=\mathrm{O}), 1593(\mathrm{Ar} \mathrm{C}=\mathrm{C}), 697(\mathrm{C}-\mathrm{Cl})$; ${ }^{1}{ }^{H}-\mathrm{NMR}$ (600 MHz, DMSO- $\left.d_{6}, \delta / \mathrm{ppm}\right): 7.93$ (dd, $\left.J=8.4,1.8 \mathrm{~Hz}, 1 \mathrm{H}, \mathrm{H}-6^{\prime}\right)$, 7.54 (d, $\left.J=7.8 \mathrm{~Hz}, 1 \mathrm{H}, \mathrm{H}-3^{\prime}\right), 7.47$ (dt, $\left.J=7.8,1.2 \mathrm{~Hz}, 1 \mathrm{H}, \mathrm{H}-5^{\prime}\right), 7.39$ (dt, $J$ $=8.4,1.8 \mathrm{~Hz}, 1 \mathrm{H}, \mathrm{H}-4$ '), $4.06\left(\mathrm{q}, J=7.2 \mathrm{~Hz}, 2 \mathrm{H},-\mathrm{OCH}_{2} \mathrm{CH}_{3}\right), 1.04(\mathrm{t}, J=7.2$ $\left.\mathrm{Hz}, 3 \mathrm{H},-\mathrm{OCH}_{2} \mathrm{CH}_{3}\right) ; \operatorname{EIMS}(\mathrm{m} / \mathrm{z}): 186[\mathrm{M}+2]^{+}, 184\left[\mathrm{M}^{+}, 139\left[\mathrm{C}_{7} \mathrm{H}_{4} \mathrm{ClO}^{+}, 111\right.\right.$ $\left[\mathrm{C}_{6} \mathrm{H}_{4} \mathrm{Cl}\right]^{+}, 85\left[\mathrm{C}_{4} \mathrm{H}_{2}^{3} \mathrm{Cl}\right]^{+}, 51\left[\mathrm{C}_{4} \mathrm{H}_{3}\right]^{+}$.

\subsection{Procedure for synthesis of 2-chlorobenzohydrazide (3)}

The calculated amount of ethyl 2-chlorobenzoate $(2 ; 0.02 \mathrm{~mol})$ was dissolved in $15 \mathrm{~mL}$ methanol as solvent and then made to react with $1.3 \mathrm{~mL}$ $80 \%$ hydrazine hydrate on stirring for 3-4 hours using $100 \mathrm{~mL}$ RB flask. The reaction was supervised by TLC and after single spot, the reaction mixture was set up to distillate excess of solvent. The addition of excess of ice cold distilled water along with gentle shaking resulted in precipitation. The precipitated product was isolated through filtration, washed by $n$-hexane and finally dried. White amorphous solid; Yield: $81 \%$; M.P.: $118-120^{\circ} \mathrm{C}$; Molecular Formula: $\mathrm{C}_{7} \mathrm{H}_{7} \mathrm{ClN}_{2} \mathrm{O}$; Molecular Weight: $170 \mathrm{gmol}^{-1}$; IR $\left(\mathrm{KBr}, v_{\max } / \mathrm{cm}^{-1}\right): 3327(\mathrm{~N}-\mathrm{H})$, $3122\left(\mathrm{Ar}^{2} \mathrm{C}-\mathrm{H}\right), 1655(\mathrm{C}=\mathrm{O}), 1613(\mathrm{Ar} \mathrm{C}=\mathrm{C}), 702(\mathrm{C}-\mathrm{Cl}) ;{ }^{1} \mathrm{H}-\mathrm{NMR}(600 \mathrm{MHz}$, DMSO- $\left.d_{6}, \delta / \mathrm{ppm}\right): 9.36(\mathrm{~s}, 1 \mathrm{H}, \mathrm{CONH}), 8.74(\mathrm{~s}, 2 \mathrm{H}, \mathrm{N}-\mathrm{H}), 7.91(\mathrm{dd}, J=8.4$, $\left.1.2 \mathrm{~Hz}, 1 \mathrm{H}, \mathrm{H}-6^{\prime}\right), 7.52\left(\mathrm{~d}, J=7.2 \mathrm{~Hz}, 1 \mathrm{H}, \mathrm{H}-3^{\prime}\right), 7.49$ (t, $J=7.8 \mathrm{~Hz}, 1 \mathrm{H}$, H-5'), 7.39 (t, $\left.J=7.8 \mathrm{~Hz}, 1 \mathrm{H}, \mathrm{H}-4^{\prime}\right)$; EIMS $(\mathrm{m} / \mathrm{z}): 172[\mathrm{M}+2]^{+}, 170[\mathrm{M}]^{+}, 139$ $\left[\mathrm{C}_{7} \mathrm{H}_{4} \mathrm{ClO}\right]^{+}, 111\left[\mathrm{C}_{6} \mathrm{H}_{4} \mathrm{Cl}\right]^{+}, 85\left[\mathrm{C}_{4} \mathrm{H}_{2} \mathrm{Cl}\right]^{+}, 51\left[\mathrm{C}_{4} \mathrm{H}_{3}\right]^{+}$.

2.4. Procedure for synthesis of 5-(2-chlorophenyl)-1,3,4-Oxadiazol-2thiol (4)

2-Chlorobenzohydrazide $(3 ; 0.03 \mathrm{~mol})$ was introduced to $70 \mathrm{~mL}$ absolute ethanol as solvent in a $250 \mathrm{~mL}$ RB flask and was then solid $\mathrm{KOH}(0.03 \mathrm{~mol})$ was added and dissolved on reflux. After cooling the system to RT, the CS, $(0.06 \mathrm{~mol})$ was poured and refluxed for further 5-6 hours. After confirming the reaction through TLC, the excess of solvent was distilled off. Then excess of cold distilled water was poured and shook to clarify the solution. The $\mathrm{pH}$ was adjusted to $5-6$ by the addition of $2-3 \mathrm{~mL}$ dilute $\mathrm{HCl}$ and the reaction mixture was aged for 15-20 minutes. The so obtained precipitates were afforded after filtration, washing by distilled water and drying. White amorphous solid; Yield: 83\%; M.P.: $172-174^{\circ} \mathrm{C}$; Molecular Formula: $\mathrm{C}_{8} \mathrm{H}_{5} \mathrm{ClN}_{2} \mathrm{OS}$; Molecular Weight: $212 \mathrm{gmol}^{-1}$; IR $\left(\mathrm{KBr}, v_{\max } / \mathrm{cm}^{-1}\right): 3122(\mathrm{Ar} \mathrm{C}-\mathrm{H}), 1670(\mathrm{C}=\mathrm{N}), 1593(\mathrm{Ar} \mathrm{C}=\mathrm{C})$, 1254 (C-O-C), 704 (C-Cl), 617 (C-S); ${ }^{1} \mathrm{H}-\mathrm{NMR}(600 \mathrm{MHz}, \mathrm{DMSO}-d, \delta / \mathrm{ppm})$ : 7.95 (dd, $J=9.0,1.2 \mathrm{~Hz}, 1 \mathrm{H}, \mathrm{H}-6^{\prime}$ ), 7.51 (d, $J=7.8 \mathrm{~Hz}, 1 \mathrm{H}, \mathrm{H}-3$ '), 7.49 (dt, $J$ $\left.=7.8,1.8 \mathrm{~Hz}, 1 \mathrm{H}, \mathrm{H}-5^{\prime}\right), 7.43\left(\mathrm{dt}, J=7.8,1.2 \mathrm{~Hz}, 1 \mathrm{H}, \mathrm{H}-4^{\prime}\right)$; EIMS $(\mathrm{m} / \mathrm{z}): 214$ $[\mathrm{M}+2]^{+}, 212[\mathrm{M}]^{+}, 153\left[\mathrm{C}_{7} \mathrm{H}_{4} \mathrm{ClNO}\right]^{+}, 139\left[\mathrm{C}_{7} \mathrm{H}_{4} \mathrm{ClO}\right]^{+}, 137\left[\mathrm{C}_{7} \mathrm{H}_{4} \mathrm{ClN}\right]^{+}, 111$ $\left[\mathrm{C}_{6} \mathrm{H}_{4} \mathrm{Cl}\right]^{+}, 85\left[\mathrm{C}_{4} \mathrm{H}_{2} \mathrm{Cl}\right]^{+}, 51\left[\mathrm{C}_{4} \mathrm{H}_{3}\right]^{+}$.

2.5. General procedure for synthesis of $\mathrm{N}$-substituted-2bromoacetamide (6a-f)

The aryl/alkyl amines (5a-f; $0.011 \mathrm{~mol})$ were suspended in $15 \mathrm{~mL}$ distilled water in a $100 \mathrm{~mL} \mathrm{RB}$ flask. The $\mathrm{pH}$ of suspension was adjusted to $8-10$ by aqueous $\mathrm{Na}_{2} \mathrm{CO}_{3}$ solution (10\%). Then equimolar 2-bromoacetyl bromide was added drop wise along with vigorous shaking. After complete addition, the 
reaction was set to stir for 1 hour. The formed precipitates were filtered, washed with cold distilled water and dried to afford the titled electrophiles.

2.6. General procedure for synthesis of $\mathrm{N}$-substituted-2-((5-(2chlorophenyl)-1,3,4-Oxadiazol-2-yl)sulfanyl)acetamide (7a-f)

The molecule $4(0.0007 \mathrm{~mol})$ was mixed with $10 \mathrm{~mL} N, N-$ dimethylformamide (DMF) and stirred for 0.5 hour with $\mathrm{NaH}(0.0007 \mathrm{~mol})$ in $100 \mathrm{~mL} \mathrm{RB}$ flask. Then the $N$-substituted-2-bromoacetamide, 6a-f, were introduced in equimolar ratios and stirring was continued for next 4-5 hours. The reaction was supervised by TLC. After single spot on TLC, excess of chilled distilled water was added to the reaction mixture along with shaking and the products appeared as precipitates. The precipitates were afforded after filtration, washing by distilled water and drying.

2.6.1. 2-(5-(2-Chlorophenyl)-1,3,4-Oxadiazol-2-yl)sulfanyl)- $\mathrm{N}-(2-$ (methoxycarbonyl) phenyl)acetamide (7a)

White amorphous solid; Yield: $80 \%$; M.P: $86-88{ }^{\circ} \mathrm{C}$; Molecular Formula: $\mathrm{C}_{18} \mathrm{H}_{14} \mathrm{ClN}_{3} \mathrm{O}_{4} \mathrm{~S}$; Molecular Weight: $403 \mathrm{gmol}^{-1}$; IR $\left(\mathrm{KBr}, v_{\max } / \mathrm{cm}^{-1}\right): 3373(\mathrm{~N}-$ $\mathrm{H}), 3092(\mathrm{C}-\mathrm{H}), 1675(\mathrm{C}=\mathrm{N}), 1647(\mathrm{C}=\mathrm{O}), 1583(\mathrm{C}=\mathrm{C}), 1297(\mathrm{C}-\mathrm{O}-\mathrm{C}), 699$ (C-Cl), 639 (C-S); ${ }^{1} \mathrm{H}-\mathrm{NMR}\left(400 \mathrm{MHz}, \mathrm{CDCl}_{3}, \delta / \mathrm{ppm}\right) ; 11.6$ (s, $\left.1 \mathrm{H},-\mathrm{NH}\right)$, 8.64 (d, $J=8.4 \mathrm{~Hz}, 1 \mathrm{H}, \mathrm{H}-6$ '"), 8.01 (dd, $J=8.0,1.2 \mathrm{~Hz}, 1 \mathrm{H}, \mathrm{H}-3$ '”) $), 7.91$ (dd, $\left.J=8.0,1.6 \mathrm{~Hz}, 1 \mathrm{H}, \mathrm{H}-6^{\prime}\right), 7.53$ (d, $J=7.6 \mathrm{~Hz}, 1 \mathrm{H}, \mathrm{H}-3^{\prime}$ ), 7.45 (dt, $J=$ 7.6, $\left.1.2 \mathrm{~Hz}, 1 \mathrm{H}, \mathrm{H}-5^{\prime}\right), 7.38$ (dt, $J=8.0,0.8 \mathrm{~Hz}, 1 \mathrm{H}, \mathrm{H}-4$ '), 7.52 (t, $J=7.6 \mathrm{~Hz}$, 1H, H-5"'), 7.10 (t, $J=7.6 \mathrm{~Hz}, 1 \mathrm{H}, \mathrm{H}-4$ "'), 4.22 (s, 2H, H-2"), 3.86 (s, 3H, $\mathrm{CH}_{3} \mathrm{OOC}-3$ '"'); EIMS $(\mathrm{m} / \mathrm{z}): 405[\mathrm{M}+2]^{+}, 403[\mathrm{M}]^{+}, 344\left[\mathrm{C}_{16} \mathrm{H}_{11} \mathrm{ClN}_{3} \mathrm{O}_{2} \mathrm{~S}\right]^{+}, 253$ $\left[\mathrm{C}_{10} \mathrm{H}_{6} \mathrm{ClN}_{2} \mathrm{O}_{2} \mathrm{~S}\right]^{+}, 226\left[\mathrm{C}_{9} \mathrm{H}_{7} \mathrm{ClN}_{2} \mathrm{OS}\right]^{+}, 224\left[\mathrm{C}_{10} \mathrm{H}_{10} \mathrm{NO}_{3} \mathrm{~S}^{+}, 193\left[\mathrm{C}_{9} \mathrm{H}_{7} \mathrm{NO}_{2} \mathrm{~S}\right]^{+}\right.$, $179\left[\mathrm{C}_{8} \mathrm{H}_{4} \mathrm{ClN}_{2} \mathrm{O}\right]^{+}, 178\left[\mathrm{C}_{9} \mathrm{H}_{8} \mathrm{NO}_{3}\right]^{+}, 153\left[\mathrm{C}_{7} \mathrm{H}_{4} \mathrm{ClNO}\right]^{+}, 151\left[\mathrm{C}_{8} \mathrm{H}_{9} \mathrm{NO}_{2}\right]^{+}, 139$ $\left[\mathrm{C}_{7} \mathrm{H}_{4} \mathrm{ClO}\right]^{+}, 137\left[\mathrm{C}_{7} \mathrm{H}_{4} \mathrm{ClN}\right]^{+}, 119\left[\mathrm{C}_{7} \mathrm{H}_{5} \mathrm{NO}\right]^{+}, 111\left[\mathrm{C}_{6} \mathrm{H}_{4} \mathrm{Cl}\right]^{+}, 90\left[\mathrm{C}_{7} \mathrm{H}_{6}\right]^{+}, 77$ $\left[\mathrm{C}_{6} \mathrm{H}_{5}\right]^{+}$.

2.6.2. 2-((5-(2-Chlorophenyl)-1,3,4-Oxadiazol-2-yl)sulfanyl)- $\mathrm{N}$-(2methylphenyl) acetamide (7b)

White amorphous solid; Yield: 91\%; M.P: $112-114^{\circ} \mathrm{C}$; Molecular Formula: $\mathrm{C}_{17} \mathrm{H}_{14} \mathrm{ClN}_{3} \mathrm{O}_{2} \mathrm{~S}$; Molecular Weight: $359 \mathrm{gmol}^{-1}$; IR $\left(\mathrm{KBr}, v_{\text {mor }} / \mathrm{cm}^{-1}\right): 3313(\mathrm{~N}-$ $\mathrm{H}), 3025(\mathrm{C}-\mathrm{H}), 1649(\mathrm{C}=\mathrm{N}), 1639(\mathrm{C}=\mathrm{O}), 1591(\mathrm{C}=\mathrm{C}), 1221(\mathrm{C}-\mathrm{O}-\mathrm{C}), 627$ (C-Cl), 621 (C-S); ${ }^{1} \mathrm{H}-\mathrm{NMR}\left(400 \mathrm{MHz}, \mathrm{CDCl}_{3}, \delta / \mathrm{ppm}\right): 8.85$ (s, $\left.1 \mathrm{H},-\mathrm{NH}\right)$, 7.90 (dd, $J=7.6,1.2 \mathrm{~Hz}, 1 \mathrm{H}, \mathrm{H}-6$ ') 7.53 (d, $\left.J=7.6 \mathrm{~Hz}, 1 \mathrm{H}, \mathrm{H}-3^{\prime}\right), 7.49$ (dt, $J$ $\left.=7.6,1.2 \mathrm{~Hz}, 1 \mathrm{H}, \mathrm{H}-5^{\prime}\right), 7.41\left(\mathrm{t}, J=7.6 \mathrm{~Hz}, 1 \mathrm{H}, \mathrm{H}-4^{\prime}\right), 7.39(\mathrm{~d}, J=7.6 \mathrm{~Hz}, 1 \mathrm{H}$, H-6"'), 7.23 (d, $J=7.6 \mathrm{~Hz}, 1 \mathrm{H}, \mathrm{H}-3$ "'), 7.16 (t, $J=7.6 \mathrm{~Hz}, 1 \mathrm{H}, \mathrm{H}-5$ '”), 7.05 (t, $J=7.6 \mathrm{~Hz}, 1 \mathrm{H}, \mathrm{H}-4$ "'), 4.05 (s, 2H, H-2"), 3.26 (s, 3H, $\mathrm{CH}_{3}-2$ "'); EIMS $(\mathrm{m} / \mathrm{z}): 361[\mathrm{M}+2]^{+}, 359[\mathrm{M}]^{+}, 253\left[\mathrm{C}_{10} \mathrm{H}_{6} \mathrm{ClN}_{2} \mathrm{O}_{2} \mathrm{~S}\right]^{+}, 226\left[\mathrm{C}_{9} \mathrm{H}_{7} \mathrm{ClN}_{2} \mathrm{OS}\right]^{+}, 222$ $\left[\mathrm{C}_{10} \mathrm{H}_{10} \mathrm{~N}_{2} \mathrm{O}_{2} \mathrm{~S}\right]^{+}, 193\left[\mathrm{C}_{9} \mathrm{H}_{7} \mathrm{NO}_{2} \mathrm{~S}\right]^{+}, 179\left[\mathrm{C}_{8} \mathrm{H}_{4} \mathrm{ClN}_{2} \mathrm{O}\right]^{+}, 152\left[\mathrm{C}_{7} \mathrm{H}_{3} \mathrm{ClNO}\right]^{+}, 139$ $\left[\mathrm{C}_{7} \mathrm{H}_{4} \mathrm{ClO}\right]^{+}, 138\left[\mathrm{C}_{7} \mathrm{H}_{5} \mathrm{ClN}\right]^{+}, 137\left[\mathrm{C}_{7} \mathrm{H}_{4} \mathrm{ClN}\right]^{+}, 120\left[\mathrm{C}_{7} \mathrm{H}_{6} \mathrm{NO}\right]^{+}, 107\left[\mathrm{C}_{7} \mathrm{H}_{9} \mathrm{~N}\right]^{+}$, $91\left[\mathrm{C}_{7} \mathrm{H}_{7}\right]^{+}, 77\left[\mathrm{C}_{6} \mathrm{H}_{5}\right]^{+}$

2.6.3. 2-((5-(2-Chlorophenyl)-1,3,4-Oxadiazol-2-yl)sulfanyl)- $\mathrm{N}$-(3methylphenyl) acetamide (7c)

Grey amorphous solid; Yield: $81 \%$; M.P: $88-90{ }^{\circ} \mathrm{C}$; Molecular Formula: $\mathrm{C}_{17} \mathrm{H}_{14} \mathrm{ClN}_{3} \mathrm{O}_{2} \mathrm{~S}$; Molecular Weight: $359 \mathrm{gmol}^{-1} ; \mathrm{IR}\left(\mathrm{KBr}, v_{\text {og }} / \mathrm{cm}^{-1}\right): 3353(\mathrm{~N}-$ $\mathrm{H}), 3075(\mathrm{C}-\mathrm{H}), 1681(\mathrm{C}=\mathrm{N}), 1677(\mathrm{C}=\mathrm{O}), 1597(\mathrm{C}=\mathrm{C}), 1290(\mathrm{C}-\mathrm{O}-\mathrm{C}), 677$ (C-Cl), 633 (C-S); ${ }^{1} \mathrm{H}-\mathrm{NMR}\left(400 \mathrm{MHz}, \mathrm{CDCl}_{3}, \delta / \mathrm{ppm}\right): 9.09$ (s, $\left.1 \mathrm{H},-\mathrm{NH}\right), 7.92$ (dd, $\left.J=7.6,1.2 \mathrm{~Hz}, 1 \mathrm{H}, \mathrm{H}-6^{\prime}\right), 7.54$ (dd, $\left.J=7.6,0.8 \mathrm{~Hz}, 1 \mathrm{H}, \mathrm{H}-3^{\prime}\right), 7.49$ (dt, $\left.J=7.6,1.2 \mathrm{~Hz}, 1 \mathrm{H}, \mathrm{H}-5^{\prime}\right), 7.43$ (dt, $\left.J=7.6 \& 1.2 \mathrm{~Hz}, 1 \mathrm{H}, \mathrm{H}-4^{\prime}\right), 7.36$ (s, $1 \mathrm{H}$, H-2"'), 7.33 (d, $J=8.0 \mathrm{~Hz}, 1 \mathrm{H}, \mathrm{H}-6$ '”), 7.18 (t, $J=8.0 \mathrm{~Hz}, 1 \mathrm{H}, \mathrm{H}-5$ '”), 6.90 (d, $J=7.6 \mathrm{~Hz}, 1 \mathrm{H}, \mathrm{H}-4$ "'), 4.01 (s, 2H, H-2"), 2.31 (3H, s, $\mathrm{CH}_{3}-3$ "'); EIMS $(\mathrm{m} / \mathrm{z}): 361[\mathrm{M}+2]^{+}, 359[\mathrm{M}]^{+}, 253\left[\mathrm{C}_{10} \mathrm{H}_{6} \mathrm{ClN}_{2} \mathrm{O}_{2} \mathrm{~S}\right]^{+}, 226\left[\mathrm{C}_{9} \mathrm{H}_{7} \mathrm{ClN}_{2} \mathrm{OS}\right]^{+}, 222$ $\left[\mathrm{C}_{10} \mathrm{H}_{10} \mathrm{~N}_{2} \mathrm{O}_{2} \mathrm{~S}\right]^{+}, 193\left[\mathrm{C}_{8} \mathrm{H}_{7} \mathrm{NO}_{2} \mathrm{~S}\right]^{+}, 179\left[\mathrm{C}_{8} \mathrm{H}_{4}^{2} \mathrm{ClN}_{2} \mathrm{O}\right]^{+}, 152\left[\mathrm{C}_{7} \mathrm{H}_{3} \mathrm{ClNO}\right]^{+}, 139$ $\left[\mathrm{C}_{7} \mathrm{H}_{4} \mathrm{ClO}\right]^{+}, 138\left[\mathrm{C}_{7} \mathrm{H}_{5} \mathrm{ClN}\right]^{+}, 137\left[\mathrm{C}_{7} \mathrm{H}_{4} \mathrm{ClN}\right]^{+}, 120\left[\mathrm{C}_{7} \mathrm{H}_{6} \mathrm{NO}\right]^{+}, 107\left[\mathrm{C}_{7} \mathrm{H}_{9} \mathrm{~N}\right]^{+}$, $91\left[\mathrm{C}_{7} \mathrm{H}_{7}\right]^{+}, 77\left[\mathrm{C}_{6} \mathrm{H}_{5}\right]^{+}$.

2.6.4. 2-(5-(2-Chlorophenyl)-1,3,4-Oxadiazol-2-yl)sulfanyl)- $\mathrm{N}$-(4methylphenyl) acetamide (7d)

Off white amorphous solid; Yield: 87\%; M.P: 92-94 ${ }^{\circ} \mathrm{C}$; Molecular Formula: $\mathrm{C}_{17} \mathrm{H}_{14} \mathrm{ClN}_{3} \mathrm{O}_{2} \mathrm{~S}$; Molecular Weight: $359 \mathrm{gmol}^{-1}$; IR $\left(\mathrm{KBr}, v_{\max } / \mathrm{cm}^{-}\right.$ 1): $3349(\mathrm{~N}-\mathrm{H}), 3068(\mathrm{C}-\mathrm{H}), 1661(\mathrm{C}=\mathrm{N}), 1644(\mathrm{C}=\mathrm{O}), 1585(\mathrm{C}=\mathrm{C}), 1247$ (C-O-C), 677 (C-Cl), 623 (C-S); ${ }^{1} \mathrm{H}-\mathrm{NMR}\left(400 \mathrm{MHz}, \mathrm{CDCl}_{3}, \delta / \mathrm{ppm}\right): 8.85$ (s, $1 \mathrm{H},-\mathrm{NH}), 7.92\left(\mathrm{dd}, J=7.6,1.2 \mathrm{~Hz}, 1 \mathrm{H}, \mathrm{H}-6^{\prime}\right), 7.55$ (d, $J=7.6 \mathrm{~Hz}, 1 \mathrm{H}, \mathrm{H}-3^{\prime}$ ), 7.49 (dt, $\left.J=7.6,1.2 \mathrm{~Hz}, 1 \mathrm{H}, \mathrm{H}-5^{\prime}\right), 7.43$ (t, $J=7.6 \mathrm{~Hz}, 1 \mathrm{H}, \mathrm{H}-4$ ') 7.41 (d, $J$ $=7.6 \mathrm{~Hz}, 2 \mathrm{H}, \mathrm{H}-2$ "' \& H-6"'), 7.11 (d, $J=8.4 \mathrm{~Hz}, 2 \mathrm{H}, \mathrm{H}-3$ " " \& H-5"'), 4.00 (s, 2H, H-2"), 2.28 (s, 3H, $\mathrm{CH}_{3}-4$ "'); EIMS (m/z): $361[\mathrm{M}+2]^{+}, 359[\mathrm{M}]^{+}, 253$ $\left[\mathrm{C}_{10} \mathrm{H}_{6} \mathrm{ClN}_{2} \mathrm{O}_{2} \mathrm{~S}\right]^{+}, 226\left[\mathrm{C}_{9} \mathrm{H}_{7} \mathrm{ClN}_{2} \mathrm{OS}\right]^{+}, 222\left[\mathrm{C}_{10} \mathrm{H}_{10} \mathrm{~N}_{2} \mathrm{O} \mathrm{S}_{2}^{+}, 193\left[\mathrm{C}_{9} \mathrm{H}_{7} \mathrm{NO}_{2} \mathrm{~S}\right]^{+}\right.$, $179\left[\mathrm{C}_{8} \mathrm{H}_{4} \mathrm{ClN}_{2} \mathrm{O}\right]^{+}, 152\left[\mathrm{C}_{7} \mathrm{H}_{3} \mathrm{ClNO}\right]^{+}, 139\left[\mathrm{C}_{7} \mathrm{H}_{4} \mathrm{ClO}\right]^{+}, 138\left[\mathrm{C}_{7} \mathrm{H}_{5} \mathrm{ClN}\right]^{+}, 137$ $\left[\mathrm{C}_{7} \mathrm{H}_{4} \mathrm{ClN}\right]^{+}, 120\left[\mathrm{C}_{7} \mathrm{H}_{6} \mathrm{NO}^{+}, 107\left[\mathrm{C}_{7} \mathrm{H}_{9} \mathrm{~N}\right]^{+}, 91\left[\mathrm{C}_{7} \mathrm{H}_{7}\right]^{+}, 77\left[\mathrm{C}_{6} \mathrm{H}_{5}\right]^{+}\right.$.

2.6.5. 2-((5-(2-Chlorophenyl)-1,3,4-Oxadiazol-2-yl)sulfanyl)- $\mathrm{N}-(\mathbf{2}-$ bromophenyl) acetamide (7e)

Off white amorphous solid; Yield: $77 \%$; M.P: $194-196{ }^{\circ} \mathrm{C}$; Molecular Formula: $\mathrm{C}_{16} \mathrm{H}_{11} \mathrm{BrClN}_{3} \mathrm{O}_{2} \mathrm{~S}$; Molecular Weight: $423 \mathrm{gmol}^{-1}$; IR $\left(\mathrm{KBr}, v_{\text {mol }}\right.$ ' $\left.\mathrm{cm}^{-1}\right): 3377(\mathrm{~N}-\mathrm{H}), 3079(\mathrm{C}-\mathrm{H}), 1679(\mathrm{C}=\mathrm{N}), 1664(\mathrm{C}=\mathrm{O}), 1591(\mathrm{C}=\mathrm{C}), 1287$
(C-O-C), 685 (C-Cl), 633 (C-S), 567 (C-Br); ${ }^{1} \mathrm{H}-\mathrm{NMR}\left(400 \mathrm{MHz}, \mathrm{CDCl}_{3}, \delta /\right.$ ppm): 9.12 (s, $1 \mathrm{H},-\mathrm{NH}), 7.91$ (dd, $J=8.0,1.2 \mathrm{~Hz}, 1 \mathrm{H}, \mathrm{H}-6$ '), 7.52 (d, $J=7.6$ $\left.\mathrm{Hz}, 1 \mathrm{H}, \mathrm{H}-3^{\prime}\right), 7.46$ (dt, $\left.J=7.6,1.2 \mathrm{~Hz}, 1 \mathrm{H}, \mathrm{H}-5^{\prime}\right), 7.41$ (dt, $J=7.6,1.6 \mathrm{~Hz}, 1 \mathrm{H}$, H-4'), 7.45-7.39 (m, 4H, H-3"' to H-6"'), 3.98 (s, 2H, H-2"'); EIMS (m/z): 427 $[\mathrm{M}+4]^{+}, 425[\mathrm{M}+2]^{+}, 423[\mathrm{M}]^{+}, 344\left[\mathrm{C}_{16} \mathrm{H}_{11} \mathrm{ClN}_{3} \mathrm{O}_{2} \mathrm{~S}\right]^{+}, 253\left[\mathrm{C}_{10} \mathrm{H}_{6} \mathrm{ClN}_{2} \mathrm{O}_{2} \mathrm{~S}\right]^{+}$, $226\left[\mathrm{C}_{9} \mathrm{H}_{7} \mathrm{ClN}_{2} \mathrm{OS}\right]^{+}, 179\left[\mathrm{C}_{8} \mathrm{H}_{4} \mathrm{ClN}_{2} \mathrm{O}\right]^{+}, 170\left[\mathrm{C}_{6} \mathrm{H}_{5} \mathrm{BrN}\right]^{+}, 139\left[\mathrm{C}_{7} \mathrm{H}_{4} \mathrm{ClO}^{+}, 137\right.$ $\left[\mathrm{C}_{7} \mathrm{H}_{4} \mathrm{ClN}\right]^{+}, 111\left[\mathrm{C}_{6} \mathrm{H}_{4} \mathrm{Cl}\right]^{+}, 77\left[\mathrm{C}_{6} \mathrm{H}_{5}\right]^{+}$

2.6.6. 2-(5-(2-Chlorophenyl)-1,3,4-Oxadiazol-2-yl)sulfanyl)- $\mathrm{N}$ (cyclohexyl)acetamide (7f)

White amorphous solid; Yield: $84 \%$; M.P: $106-108^{\circ} \mathrm{C}$; Molecular Formula: $\mathrm{C}_{16} \mathrm{H}_{18} \mathrm{ClN}_{3} \mathrm{O}_{2} \mathrm{~S}$; Molecular Weight: $351 \mathrm{gmol}^{-1}$; IR $\left(\mathrm{KBr}, v_{1} / \mathrm{cm}^{-1}\right): 3327(\mathrm{~N}-$ $\mathrm{H}), 3053(\mathrm{C}-\mathrm{H}), 1651(\mathrm{C}=\mathrm{N}), 1667(\mathrm{C}=\mathrm{O}$ str.), $1587(\mathrm{C}=\mathrm{C}), 1269(\mathrm{C}-\mathrm{O}-\mathrm{C}), 689$ (C-Cl), $652(\mathrm{C}-\mathrm{S}) ;{ }^{1} \mathrm{H}-\mathrm{NMR}\left(400 \mathrm{MHz}, \mathrm{CDCl}_{3}, \delta / \mathrm{ppm}\right) ; 9.15(\mathrm{~s}, 1 \mathrm{H},-\mathrm{NH}), 7.91$ (dd, $\left.J=7.6,1.2 \mathrm{~Hz}, 1 \mathrm{H}, \mathrm{H}-6^{\prime}\right), 7.55$ (d, $J=8.0 \mathrm{~Hz}, 1 \mathrm{H}, \mathrm{H}-3^{\prime}$ ), 7.47 (dt, $J=7.6$, $1.2 \mathrm{~Hz}, 1 \mathrm{H}, \mathrm{H}-5$ '), 7.39 (t, $\left.J=7.6 \mathrm{~Hz}, 1 \mathrm{H}, \mathrm{H}-4^{\prime}\right), 3.98$ (s, 2H, H-2"), 3.73-3.69 (m, 1H, H-1"'), 1.85-1.15 (m, 10H, H-2"” to H-6"'); EIMS (m/z): 353 [M+2] $351\left[\mathrm{M}^{+}\right], 253\left[\mathrm{C}_{10} \mathrm{H}_{6} \mathrm{ClN}_{2} \mathrm{O}_{2} \mathrm{~S}\right]^{+}, 137\left[\mathrm{C}_{7} \mathrm{H}_{4} \mathrm{ClN}\right]^{+}, 111\left[\mathrm{C}_{6} \mathrm{H}_{4} \mathrm{Cl}\right]^{+}, 77\left[\mathrm{C}_{6} \mathrm{H}_{5}\right]^{+}$

2.7. Procedure for synthesis of ethyl 2-(5-(2-chlorophenyl)-1,3,4Oxadiazol-2-ylthio)acetate (8)

The compound $4(0.03 \mathrm{~mol})$ was also taken in DMF $(18 \mathrm{~mL})$ in a 250 $\mathrm{mL} \mathrm{RB}$ flask and stirred with $\mathrm{NaH}(0.03 \mathrm{~mol})$ for 0.5 hour. Then, $0.03 \mathrm{~mol}$ ethyl 2-bromoacetate was introduced and further stirring was continued for 4-5 hours. After completion as supervised by TLC, the reaction mass transferred to a $250 \mathrm{~mL}$ conical flask and excess of cold distilled water was added to afford precipitates of title compound. The precipitates were filtered, washed by distilled water and dried for further reaction. White amorphous solid; Yield: $81 \%$; M.P.: 176-178 ${ }^{\circ} \mathrm{C}$; Molecular Formula: $\mathrm{C}_{12} \mathrm{H}_{11} \mathrm{ClN}_{2} \mathrm{O}_{3} \mathrm{~S}$; Molecular Weight: $298 \mathrm{gmol}^{-}$ ${ }^{1}$; IR $\left(\mathrm{KBr}, v / \mathrm{cm}^{-1}\right): 3146(\mathrm{Ar} \mathrm{C}-\mathrm{H}), 1748(\mathrm{C}=\mathrm{O}), 1679(\mathrm{C}=\mathrm{N}), 1602(\mathrm{Ar}$ $\mathrm{C}=\mathrm{C}), 1261$ (C-O-C), 706 (C-Cl), 607 (C-S); ${ }^{1} \mathrm{H}-\mathrm{NMR}\left(600 \mathrm{MHz}, \mathrm{DMSO}-d_{6}\right.$ $\delta / \mathrm{ppm}): 7.94$ (dd, $J=7.8,1.2 \mathrm{~Hz}, 1 \mathrm{H}, \mathrm{H}-6$ ') 7.57 (d, $\left.J=8.4 \mathrm{~Hz}, 1 \mathrm{H}, \mathrm{H}-3{ }^{\prime}\right)$, 7.44 (dt, $J=7.8,1.8 \mathrm{~Hz}, 1 \mathrm{H}, \mathrm{H}-5$ ') 7.39 (dt, $J=7.8,1.2 \mathrm{~Hz}, 1 \mathrm{H}, \mathrm{H}-4^{\prime}$ ), 4.63 (s, 2H, H-2"), 3.96 (q, $J=7.2 \mathrm{~Hz}, 2 \mathrm{H},-\mathrm{OCH}_{2} \mathrm{CH}_{3}$ ), 1.03 (t, $J=7.2 \mathrm{~Hz}, 3 \mathrm{H}$, $\left.-\mathrm{OCH}_{2} \mathrm{CH}_{3}\right) ; \operatorname{EIMS}(\mathrm{m} / \mathrm{z}): 300[\mathrm{M}+2]^{+}, 298\left[\mathrm{M}^{+}, 253\left[\mathrm{C}_{10} \mathrm{H}_{6} \mathrm{ClN}_{2} \mathrm{O}_{2} \mathrm{~S}^{+}, 225\right.\right.$ $\left[\mathrm{C}_{9} \mathrm{H}_{6} \mathrm{ClN}_{2} \mathrm{OS}\right]^{+}, 212\left[\mathrm{C}_{8} \mathrm{H}_{5} \mathrm{ClN}_{2} \mathrm{OS}\right]^{+}, 179\left[\mathrm{C}_{8} \mathrm{H}_{4} \mathrm{ClN}_{2} \mathrm{O}\right]^{+}, 153\left[\mathrm{C}_{7} \mathrm{H}_{4} \mathrm{ClNO}\right]^{+}$, $139\left[\mathrm{C}_{7} \mathrm{H}_{4}{ }_{4} \mathrm{ClO}\right]^{+}, 137\left[\mathrm{C}_{7} \mathrm{H}_{4} \mathrm{ClN}^{+}, 111\left[\mathrm{C}_{6} \mathrm{H}_{4} \mathrm{Cl}\right]^{+}, 85\left[\mathrm{C}_{4} \mathrm{H}_{2} \mathrm{Cl}\right]^{+}, 51\left[\mathrm{C}_{4} \mathrm{H}_{3}\right]^{+}\right.$.

2.8. Procedure for synthesis of 2-(5-(2-chlorophenyl)-1,3,4-Oxadiazol2-ylthio)acetohydrazide (9)

The compound $\mathbf{8}(0.03 \mathrm{~mol})$ was taken in a $250 \mathrm{~mL}$ RB flask containing 35 $\mathrm{mL}$ methanol. $80 \%$ Hydrazine hydrate $(0.03 \mathrm{~mol})$ was the second reagent and the reaction contents were simply stirred for 3-4 hours strictly at RT. The reaction was monitored by TLC till completion. The reaction contents were transferred to a $500 \mathrm{~mL}$ conical flask and the title compound was afforded by filtration after addition of excess cold distilled water, washed by $n$-hexane and dried. White amorphous solid; Yield: $81 \%$; M.P.: $180-182{ }^{\circ} \mathrm{C}$; Molecular Formula: $\mathrm{C}_{10} \mathrm{H}_{9} \mathrm{ClN}_{4} \mathrm{O}_{2} \mathrm{~S}$; Molecular Weight: $284 \mathrm{gmol}^{-1}$; IR $\left(\mathrm{KBr}, v_{\text {mox }} / \mathrm{cm}^{-1}\right): 3373(\mathrm{~N}-$ $\mathrm{H}), 3092(\mathrm{Ar} \mathrm{C}-\mathrm{H}), 1665(\mathrm{C}=\mathrm{O}), 1691(\mathrm{C}=\mathrm{N}), 1617(\mathrm{Ar} \mathrm{C}=\mathrm{C}), 1235(\mathrm{C}-\mathrm{O}-\mathrm{C})$, 711 (C-Cl), 602 (C-S); ${ }^{1} \mathrm{H}-\mathrm{NMR}$ (600 MHz, DMSO-d,$\left.\delta / \mathrm{ppm}\right): 9.88$ (s, $1 \mathrm{H}$, CONH), $8.76(\mathrm{~s}, 2 \mathrm{H}, \mathrm{N}-\mathrm{H}), 7.92\left(\mathrm{~d}, J=8.4 \mathrm{~Hz}, 1 \mathrm{H}, \mathrm{H}-6^{\prime}\right), 7.56(\mathrm{~d}, J=7.8 \mathrm{~Hz}$, 1H, H-3'), 7.44 (t, $J=8.4 \mathrm{~Hz}, 1 \mathrm{H}, \mathrm{H}-5^{\prime}$ ), 7.42 (t, $J=7.8 \mathrm{~Hz}, 1 \mathrm{H}, \mathrm{H}-4$ '), 4.68 (s, 2H, H-2"); EIMS (m/z): $286[\mathrm{M}+2]^{+}, 284[\mathrm{M}]^{+}, 253\left[\mathrm{C}_{10} \mathrm{H}_{6} \mathrm{ClN}_{2} \mathrm{O}_{2} \mathrm{~S}\right]^{+}, 225$ $\left[\mathrm{C}_{9} \mathrm{H}_{6} \mathrm{ClN}_{2} \mathrm{OS}\right]^{+}, 212\left[\mathrm{C}_{8} \mathrm{H}_{5} \mathrm{ClN}_{2} \mathrm{OS}\right]^{+}, 179\left[\mathrm{C}_{8} \mathrm{H}_{4} \mathrm{ClN}_{2} \mathrm{O}\right]^{+}, 153\left[\mathrm{C}_{7} \mathrm{H}_{4} \mathrm{ClNO}\right]^{+}$, $139\left[\mathrm{C}_{7} \mathrm{H}_{4}^{2} \mathrm{ClO}\right]^{+}, 137\left[\mathrm{C}_{7} \mathrm{H}_{4} \mathrm{ClN}\right]^{+}, 111\left[\mathrm{C}_{6} \mathrm{H}_{4} \mathrm{Cl}\right]^{+}, 85\left[\mathrm{C}_{4} \mathrm{H}_{2} \mathrm{Cl}\right]^{+}, 51\left[\mathrm{C}_{4}^{4} \mathrm{H}_{3}\right]^{+}$

2.9. General procedure for synthesis of $N$ '-substituted-2-(5-(2chlorophenyl)-1,3,4-Oxadiazol-2-ylthio)acetohydrazide (11a-i)

The molecule $9(0.002 \mathrm{~mol})$ was taken in a $50 \mathrm{~mL}$ RB flask in $12 \mathrm{~mL}$ methanol. The aryl carboxaldehydes $(\mathbf{1 0 a}-\mathbf{i} ; 0.002 \mathrm{~mol})$ were poured and further stirred for 2-3 hours. After supervision by TLC, excess of cold distilled water was added to quench the precipitates. The formed precipitates were filtered, washed with distilled water and dried.

2.9.1. $\boldsymbol{N}^{\prime}$-(2-Nitrobenzylidene)-2-(5-(2-chlorophenyl)-1,3,4-Oxadiazol2-ylthio)acetohydrazide (11a)

Shiny light yellow crystalline solid; Yield: $77 \%$; M.P.: $208-210{ }^{\circ} \mathrm{C}$; Molecular Formula: $\mathrm{C}_{17} \mathrm{H}_{12} \mathrm{ClN}_{5} \mathrm{O}_{4} \mathrm{~S}$; Molecular Weight: $417 \mathrm{gmol}^{-1}$; IR $(\mathrm{KBr}$, $\left.v / \mathrm{cm}^{-1}\right): 3083(\mathrm{Ar} \mathrm{C}-\mathrm{H}), 1672(\mathrm{C}=\mathrm{N}), 1613(\mathrm{Ar} \mathrm{C}=\mathrm{C}), 1243(\mathrm{C}-\mathrm{O}-\mathrm{C}), 701(\mathrm{C}-$ Cl), 622 (C-S); ${ }^{\prime} \mathrm{H}-\mathrm{NMR}\left(600 \mathrm{MHz}, \mathrm{DMSO}-d_{6}, \delta / \mathrm{ppm}\right): 12.01$ (s, $\left.1 \mathrm{H}, \mathrm{CONH}\right)$, 8.42 (s, $\left.\left.1 \mathrm{H}, \mathrm{H}-7^{\prime}\right)^{\prime}\right), 8.05$ (d, $\left.J=8.4 \mathrm{~Hz}, 1 \mathrm{H}, \mathrm{H}^{\prime} 6^{\prime}\right), 8.00(\mathrm{~d}, J=7.8 \mathrm{~Hz}, 1 \mathrm{H}$, H-6"'), 7.91 (d, $J=7.8 \mathrm{~Hz}, 1 \mathrm{H}, \mathrm{H}-3$ '”'), 7.78 (d, $J=7.8 \mathrm{~Hz}, 1 \mathrm{H}, \mathrm{H}-3$ '), 7.67 $\left(\mathrm{t}, J=7.8 \mathrm{~Hz}, 1 \mathrm{H}, \mathrm{H}-5^{\prime}\right), 7.62\left(\mathrm{t}, J=8.4 \mathrm{~Hz}, 1 \mathrm{H}, \mathrm{H}-4^{\prime}\right), 7.60-7.56(\mathrm{~m}, 2 \mathrm{H}$, H-4"” \& H-5"”), 4.65 (s, 2H, H-2"); EIMS ( $\mathrm{m} / \mathrm{z}): 419[\mathrm{M}+2]^{+}, 417[\mathrm{M}]^{+}, 253$ $\left[\mathrm{C}_{10} \mathrm{H}_{6} \mathrm{ClN}_{2} \mathrm{O}_{2} \mathrm{~S}\right]^{+}, 225\left[\mathrm{C}_{9} \mathrm{H}_{6} \mathrm{ClN}_{2} \mathrm{OS}\right]^{+}, 212\left[\mathrm{C}_{8} \mathrm{H}_{5} \mathrm{ClN}_{2} \mathrm{OS}\right]^{+}, 192\left[\mathrm{C}_{8} \mathrm{H}_{6} \mathrm{~N}_{3} \mathrm{O}_{3}\right]^{+}$, $179\left[\mathrm{C}_{8} \mathrm{H}_{4} \mathrm{ClN}_{2} \mathrm{O}\right]^{+}, 164\left[\mathrm{C}_{7} \mathrm{H}_{6} \mathrm{~N}_{3} \mathrm{O}_{2}\right]^{+}, 153\left[\mathrm{C}_{7} \mathrm{H}_{4} \mathrm{ClNO}^{+}, 139\left[\mathrm{C}_{7} \mathrm{H}_{4} \mathrm{ClO}\right]^{+}, 137\right.$ $\left[\mathrm{C}_{7} \mathrm{H}_{4} \mathrm{ClN}\right]^{+}, 136\left[\mathrm{C}_{7} \mathrm{H}_{6} \mathrm{NO}_{2}\right]^{+}, 111\left[\mathrm{C}_{6} \mathrm{H}_{4} \mathrm{Cl}\right]^{+}, 85\left[\mathrm{C}_{4} \mathrm{H}_{2} \mathrm{Cl}\right]^{+}, 65\left[\mathrm{C}_{5} \mathrm{H}_{5}\right]^{+}, 51$ $\left[\mathrm{C}_{4} \mathrm{H}_{3}\right]^{+}$. 
2.9.2. $N$ '-(3-Nitrobenzylidene)-2-(5-(2-chlorophenyl)-1,3,4-Oxadiazol2-ylthio)acetohydrazide (11b)

White amorphous solid; Yield: 79\%; M.P.: $218-220{ }^{\circ} \mathrm{C}$; Molecular Formula: $\mathrm{C}_{17} \mathrm{H}_{12} \mathrm{ClN}_{5} \mathrm{O}_{4} \mathrm{~S}$; Molecular Weight: $417 \mathrm{gmol}^{-1}$; IR $\left(\mathrm{KBr}, v / \mathrm{cm}^{-1}\right)$ : $3076(\mathrm{Ar} \mathrm{C}-\mathrm{H}), 1659(\mathrm{C}=\mathrm{N}), 1601(\mathrm{Ar} \mathrm{C}=\mathrm{C}), 1240$ (C-O-C), $699(\mathrm{C}-\mathrm{Cl}), 624$ (C-S); ${ }^{1} \mathrm{H}-\mathrm{NMR}\left(600 \mathrm{MHz}, \mathrm{DMSO}-d_{6}, \delta / \mathrm{ppm}\right): 12.03$ (s, 1H, CONH), 8.57 (t, $J=1.2 \mathrm{~Hz}, 1 \mathrm{H}, \mathrm{H}-2$ "'), 8.37 (s, 1H, H-7"'), 8.20 (d, $J=8.4 \mathrm{~Hz}, 1 \mathrm{H}, \mathrm{H}-6 "$ "), 8.12 (d, $J=7.8 \mathrm{~Hz}, 1 \mathrm{H}, \mathrm{H}-6$ '), 8.06 (d, $J=8.4 \mathrm{~Hz}, 1 \mathrm{H}, \mathrm{H}-4$ '”), 7.85 (t, $J=8.4$ $\mathrm{Hz}, 1 \mathrm{H}, \mathrm{H}-5$ '”), 7.72 (d, $J=7.8 \mathrm{~Hz}, 1 \mathrm{H}, \mathrm{H}-3$ '), 7.58 (d, $J=7.8 \mathrm{~Hz}, 1 \mathrm{H}, \mathrm{H}-5$ '), $7.53\left(\mathrm{t}, J=7.8 \mathrm{~Hz}, 1 \mathrm{H}, \mathrm{H}-4\right.$ '), 4.71 (s, 2H, H-2"); $\operatorname{EIMS}(\mathrm{m} / \mathrm{z}): 419[\mathrm{M}+2]^{+}$, $417[\mathrm{M}]^{+}, 253\left[\mathrm{C}_{10} \mathrm{H}_{6} \mathrm{ClN}_{2} \mathrm{O}_{2} \mathrm{~S}\right]^{+}, 225\left[\mathrm{C}_{9} \mathrm{H}_{6} \mathrm{ClN}_{2} \mathrm{OS}\right]^{+}, 212\left[\mathrm{C}_{8} \mathrm{H}_{5} \mathrm{ClN}_{2} \mathrm{OS}\right]^{+}, 192$ $\left[\mathrm{C}_{8} \mathrm{H}_{6} \mathrm{~N}_{3} \mathrm{O}_{3}\right]^{+}, 179\left[\mathrm{C}_{8} \mathrm{H}_{4} \mathrm{ClN}_{2} \mathrm{O}\right]^{+}, 164\left[\mathrm{C}_{7} \mathrm{H}_{6} \mathrm{~N}_{3} \mathrm{O}_{2}\right]^{+}, 153\left[\mathrm{C}_{7} \mathrm{H}_{4} \mathrm{ClNO}\right]^{+}, 139$ $\left[\mathrm{C}_{7} \mathrm{H}_{4} \mathrm{ClO}\right]^{+}, 137\left[\mathrm{C}_{7} \mathrm{H}_{4} \mathrm{ClN}\right]^{+}, 136\left[\mathrm{C}_{7} \mathrm{H}_{6} \mathrm{NO}_{2}\right]^{+}, 111\left[\mathrm{C}_{6} \mathrm{H}_{4} \mathrm{Cl}\right]^{+}, 85\left[\mathrm{C}_{4} \mathrm{H}_{2} \mathrm{Cl}\right]^{+}$ $65\left[\mathrm{C}_{5} \mathrm{H}_{5}\right]^{+}, 51\left[\mathrm{C}_{4} \mathrm{H}_{3}\right]^{+}$

2.9.3. $N$ '-(4-Nitrobenzylidene)-2-(5-(2-chlorophenyl)-1,3,4-Oxadiazol2-ylthio)acetohydrazide (11c)

Yellow amorphous solid; Yield: $83 \%$; M.P.: $236-238{ }^{\circ} \mathrm{C}$; Molecular Formula: $\mathrm{C}_{17} \mathrm{H}_{12} \mathrm{ClN}_{5} \mathrm{O}_{4} \mathrm{~S}$; Molecular Weight: $417 \mathrm{gmol}^{-1}$; IR $\left(\mathrm{KBr}, v_{\text {max }} / \mathrm{cm}^{-1}\right)$ : $3085(\mathrm{Ar} \mathrm{C}-\mathrm{H}), 1661(\mathrm{C}=\mathrm{N}), 1619(\mathrm{Ar} \mathrm{C}=\mathrm{C}), 1238(\mathrm{C}-\mathrm{O}-\mathrm{C}), 703(\mathrm{C}-\mathrm{Cl}), 619$ (C-S); ${ }^{1} \mathrm{H}-\mathrm{NMR}(600 \mathrm{MHz}, \mathrm{DMSO}-d$, $\delta / \mathrm{ppm}): 11.89(\mathrm{~s}, 1 \mathrm{H}, \mathrm{CONH}), 8.36$ (s, 1H, H-7'"'), 8.22 (d, $\left.J=8.4 \mathrm{~Hz}, 1 \mathrm{H}, \mathrm{H}-6^{\prime}\right), 8.17$ (d, $J=8.4 \mathrm{~Hz}, 2 \mathrm{H}, \mathrm{H}-2$ "' \& H-6"'), 7.92 (d, $J=8.4 \mathrm{~Hz}, 2 \mathrm{H}, \mathrm{H}-3$ "” \& H-5"'), 7.67 (d, $J=7.8 \mathrm{~Hz}, 1 \mathrm{H}$, H-3'), 7.61 (t, $\left.J=8.4 \mathrm{~Hz}, 1 \mathrm{H}, \mathrm{H}-5^{\prime}\right), 7.58$ (t, $\left.J=7.8 \mathrm{~Hz}, 1 \mathrm{H}, \mathrm{H}-4^{\prime}\right), 4.74$ (s, 2H, H-2"); EIMS (m/z): $419[\mathrm{M}+2]^{+}, 417\left[\mathrm{M}^{+}, 253\left[\mathrm{C}_{10} \mathrm{H}_{6} \mathrm{ClN}_{2} \mathrm{O}_{2} \mathrm{~S}^{+}, 225\right.\right.$ $\left[\mathrm{C}_{8} \mathrm{H}_{6} \mathrm{ClN}_{2} \mathrm{OS}\right]^{+}, 212\left[\mathrm{C}_{8} \mathrm{H}_{5} \mathrm{ClN}_{2} \mathrm{OS}\right]^{+}, 192\left[\mathrm{C}_{8} \mathrm{H}_{6} \mathrm{~N}_{3} \mathrm{O}_{3}\right]^{+}, 179\left[\mathrm{C}_{8} \mathrm{H}_{4} \mathrm{ClN}_{2} \mathrm{O}\right]^{+}$, $164\left[\mathrm{C}_{7} \mathrm{H}_{6} \mathrm{~N}_{3} \mathrm{O}_{2}\right]^{+}, 153\left[\mathrm{C}_{7} \mathrm{H}_{4} \mathrm{ClNO}\right]^{+}, 139\left[\mathrm{C}_{7} \mathrm{H}_{4} \mathrm{ClO}\right]^{+}, 137\left[\mathrm{C}_{7} \mathrm{H}_{4} \mathrm{ClN}^{+}, 136\right.$ $\left[\mathrm{C}_{7} \mathrm{H}_{6} \mathrm{NO}_{2}\right]^{+}, 111\left[\mathrm{C}_{6} \mathrm{H}_{4} \mathrm{Cl}\right]^{+}, 85\left[\mathrm{C}_{4} \mathrm{H}_{2} \mathrm{Cl}\right]^{+}, 65\left[\mathrm{C}_{5} \mathrm{H}_{5}\right]^{+}, 51\left[\mathrm{C}_{4} \mathrm{H}_{3}\right]^{+}$.

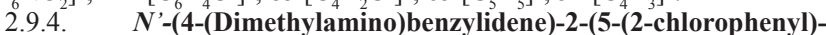
1,3,4-Oxadiazol-2-ylthio)acetohydrazide (11d)

Yellow white amorphous solid; Yield: $83 \%$; M.P.: $164-166^{\circ} \mathrm{C}$; Molecular Formula: $\mathrm{C}_{10} \mathrm{H}_{18} \mathrm{ClN}_{5} \mathrm{O}_{2} \mathrm{~S}$; Molecular Weight: $415 \mathrm{gmol}^{-1}$; IR $\left(\mathrm{KBr}, v / \mathrm{cm}^{-1}\right)$ : $3049(\mathrm{Ar} \mathrm{C}-\mathrm{H}), 1683(\mathrm{C}=\mathrm{N}), 1622(\mathrm{Ar} \mathrm{C}=\mathrm{C}), 1247(\mathrm{C}-\mathrm{O}-\mathrm{C}), 706(\mathrm{C}-\mathrm{Cl}), 626$ (C-S); ${ }^{1} \mathrm{H}-\mathrm{NMR}(600 \mathrm{MHz}, \mathrm{DMSO}-d$, $\delta / \mathrm{ppm}): 11.57$ (s, $\left.1 \mathrm{H}, \mathrm{CONH}\right), 8.05(\mathrm{~s}$, $1 \mathrm{H}, \mathrm{H}-7$ '”), 7.94 (dd, $J=7.8,2.4 \mathrm{~Hz}, 1 \mathrm{H}, \mathrm{H}-6$ '), 7.63 (d, $J=7.8 \mathrm{~Hz}, 1 \mathrm{H}, \mathrm{H}-3$ '), 7.49 (d, $J=9.0 \mathrm{~Hz}, 2 \mathrm{H}, \mathrm{H}-2$ "' \& H-6"') 7.31 (t, $J=8.4 \mathrm{~Hz}, 1 \mathrm{H}, \mathrm{H}-5$ ') 7.20 (t, $J=8.4 \mathrm{~Hz}, 1 \mathrm{H}, \mathrm{H}-4$ '), 6.71 (d, $J=9.0 \mathrm{~Hz}, 2 \mathrm{H}, \mathrm{H}-3$ "' \& H-5"'), 4.63 (s, $2 \mathrm{H}, \mathrm{H}-2$ ") 3.04 (s, 6H, (CH $)_{2} \mathrm{~N}-4$ "'); $\operatorname{EIMS}(\mathrm{m} / \mathrm{z}): 417[\mathrm{M}+2]^{+}, 415[\mathrm{M}]^{+}, 253$ $\left[\mathrm{C}_{10} \mathrm{H}_{6} \mathrm{ClN}_{2} \mathrm{O}_{2} \mathrm{~S}\right]^{+}, 225\left[\mathrm{C}_{9} \mathrm{H}_{6} \mathrm{ClN}_{2} \mathrm{OS}\right]^{+}, 212\left[\mathrm{C}_{8} \mathrm{H}_{5} \mathrm{ClN}_{2} \mathrm{OS}\right]^{+}, 190\left[\mathrm{C}_{10} \mathrm{H}_{12} \mathrm{~N}_{3} \mathrm{O}\right]^{+}$, $179\left[\mathrm{C}_{8} \mathrm{H}_{4} \mathrm{ClN}_{2} \mathrm{O}\right]^{+}, 162\left[\mathrm{C}_{9} \mathrm{H}_{12} \mathrm{~N}_{3}\right]^{+}, 153\left[\mathrm{C}_{7} \mathrm{H}_{4} \mathrm{ClNO}^{+}, 139\left[\mathrm{C}_{7} \mathrm{H}_{4} \mathrm{ClO}\right]^{+}, 137\right.$ $\left[\mathrm{C}_{7} \mathrm{H}_{4} \mathrm{ClN}\right]^{+}, 133\left[\mathrm{C}_{9} \mathrm{H}_{11} \mathrm{~N}\right]^{+}, 111\left[\mathrm{C}_{6} \mathrm{H}_{4} \mathrm{Cl}\right]^{+}, 85\left[\mathrm{C}_{4} \mathrm{H}_{2} \mathrm{Cl}\right]^{+}, 65\left[\mathrm{C}_{5} \mathrm{H}_{5}\right]^{+}, 51$ $\left[\mathrm{C}_{4} \mathrm{H}_{3}\right]^{+}$.

2.9.5. $\quad N^{\prime}$-(4-(Diethylamino)benzylidene)-2-(5-(2-chlorophenyl)-1,3,4Oxadiazol-2-ylthio)acetohydrazide (11e)

Light yellow amorphous solid; Yield: $75 \%$; M.P.: $170-172{ }^{\circ} \mathrm{C}$; Molecular Formula: $\mathrm{C}_{21} \mathrm{H}_{22} \mathrm{ClN}_{5} \mathrm{O}_{2} \mathrm{~S}$; Molecular Weight: $443 \mathrm{gmol}^{-1}$; IR $\left(\mathrm{KBr}, v_{\text {mar }} / \mathrm{cm}^{-1}\right)$ : $3056(\mathrm{Ar} \mathrm{C}-\mathrm{H}), 1638(\mathrm{C}=\mathrm{N}), 1617(\mathrm{Ar} \mathrm{C}=\mathrm{C}), 1241(\mathrm{C}-\mathrm{O}-\mathrm{C}), 708(\mathrm{C}-\mathrm{Cl}), 623$ (C-S); ${ }^{1} \mathrm{H}-\mathrm{NMR}(600 \mathrm{MHz}, \mathrm{DMSO}-\mathrm{d}$, $\delta / \mathrm{ppm}): 11.51(\mathrm{~s}, 1 \mathrm{H}, \mathrm{CONH}), 8.06$ (s, 1H, H-7'”'), 7.97 (d, $\left.J=8.4 \mathrm{~Hz}, 1 \mathrm{H}, \mathrm{H}^{\prime} 6^{\prime}\right), 7.61$ (d, $\left.J=7.8 \mathrm{~Hz}, 1 \mathrm{H}, \mathrm{H}-3^{\prime}\right)$ 7.49 (d, $J=9.0 \mathrm{~Hz}, 2 \mathrm{H}, \mathrm{H}-2$ " \& \& H-6"'), 7.25 (t, $J=7.8 \mathrm{~Hz}, 1 \mathrm{H}, \mathrm{H}-5$ ') 7.11 (t, $J=7.8 \mathrm{~Hz}, 1 \mathrm{H}, \mathrm{H}-4$ '), 6.67 (d, $J=9.0 \mathrm{~Hz}, 2 \mathrm{H}, \mathrm{H}-3$ '” \& H-5"'), 4.64 (s, $2 \mathrm{H}, \mathrm{H}-2 "), 3.39$ (q, $J=7.2 \mathrm{~Hz}, 4 \mathrm{H},\left(\mathrm{CH}_{3} \mathrm{CH}_{2}\right) \mathrm{N}-4$ "') $1.13(\mathrm{t}, J=7.2 \mathrm{~Hz}, 6 \mathrm{H}$, $\left(\mathrm{CH}_{3} \mathrm{CH}_{2}\right)_{2} \mathrm{~N}-4$ "'); EIMS $(\mathrm{m} / \mathrm{z}): 445[\mathrm{M}+2]^{+}, 443[\mathrm{M}]^{+}, 253\left[\mathrm{C}_{10} \mathrm{H}_{6} \mathrm{ClN}_{2} \mathrm{O}_{2} \mathrm{~S}\right]^{+}$, $225\left[\mathrm{C}_{9} \mathrm{H}_{6} \mathrm{ClN}_{2} \mathrm{OS}\right]^{+}, 218\left[\mathrm{C}_{12} \mathrm{H}_{16} \mathrm{~N}_{3} \mathrm{O}\right]^{+}, 212\left[\mathrm{C}_{8} \mathrm{H}_{5} \mathrm{ClN}_{2} \mathrm{OS}\right]^{+}, 190\left[\mathrm{C}_{11} \mathrm{H}_{16} \mathrm{~N}_{3}\right]^{+}$, $179\left[\mathrm{C}_{8} \mathrm{H}_{4} \mathrm{ClN}_{2} \mathrm{O}\right]^{+}, 162\left[\mathrm{C}_{11} \mathrm{H}_{15} \mathrm{~N}^{3}, 153\left[\mathrm{C}_{7} \mathrm{H}_{4} \mathrm{ClNO}^{+}, 139\left[\mathrm{C}_{7} \mathrm{H}_{4} \mathrm{ClO}\right]^{+}, 137\right.\right.$ $\left[\mathrm{C}_{7} \mathrm{H} \mathrm{ClN}_{4}^{+}, 111\left[\mathrm{C}_{6} \mathrm{H} \mathrm{Cl}_{4}\right]^{+}, 85\left[\mathrm{C}_{4} \mathrm{H}_{2} \mathrm{Cl}\right]^{+}, 65\left[\mathrm{C}_{5} \mathrm{H}_{5}\right]^{+}, 51\left[\mathrm{C}_{4} \mathrm{H}_{3}\right]^{+}\right.$.

2.9.6. $\quad N^{\prime}$-(2,3-Dimethoxybenzylidene)-2-(5-(2-chlorophenyl)-1,3,4Oxadiazol-2-ylthio)acetohydrazide (11f)

White amorphous solid; Yield: $85 \%$; M.P.: $160-162{ }^{\circ} \mathrm{C}$; Molecular Formula: $\mathrm{C}_{10} \mathrm{H}_{17} \mathrm{ClN}_{4} \mathrm{O}_{4} \mathrm{~S}$; Molecular Weight: $432 \mathrm{gmol}^{-1}$; IR $\left(\mathrm{KBr}, v_{\text {mol }} / \mathrm{cm}^{-1}\right)$ $3067(\mathrm{Ar} \mathrm{C}-\mathrm{H}), 1639(\mathrm{C}=\mathrm{N}), 1604(\mathrm{Ar} \mathrm{C}=\mathrm{C}), 1237(\mathrm{C}-\mathrm{O}-\mathrm{C}), 703(\mathrm{C}-\mathrm{Cl}), 627$ (C-S); ${ }^{1} \mathrm{H}-\mathrm{NMR}$ (600 MHz, DMSO- $d$, $\left.\delta / \mathrm{ppm}\right): 11.74(\mathrm{~s}, 1 \mathrm{H}, \mathrm{CONH}), 8.36$ (s, $1 \mathrm{H}, \mathrm{H}-7$ '”), 7.93 (dd, $J=9.0,1.8 \mathrm{~Hz}, 1 \mathrm{H}, \mathrm{H}-6$ '), $7.72(\mathrm{~d}, J=8.4 \mathrm{~Hz}, 1 \mathrm{H}$, H-3'), 7.66 (t, $J=7.8 \mathrm{~Hz}, 1 \mathrm{H}, \mathrm{H}-5$ '), 7.58 (t, $J=7.8 \mathrm{~Hz}, 1 \mathrm{H}, \mathrm{H}-4^{\prime}$ ), 7.43 (dd, $J=7.8,3.0 \mathrm{~Hz}, 1 \mathrm{H}, \mathrm{H}-6$ "'), 7.12 (dd, $J=9.0,3.0 \mathrm{~Hz}, 1 \mathrm{H}, \mathrm{H}-4$ "'), 7.09 (t, $J=$ $7.8 \mathrm{~Hz}, 1 \mathrm{H}, \mathrm{H}-5$ "'), 4.63 (s, 2H, H-2"), 3.84 (s, 3H, CH $\mathrm{O}-3$ "'), 3.79 (s, 3H, $\mathrm{CH}_{3} \mathrm{O}-2$ "'); $\operatorname{EIMS}(\mathrm{m} / \mathrm{z}): 434[\mathrm{M}+2]^{+}, 432\left[\mathrm{M}^{+}, 253\left[\mathrm{C}_{10} \mathrm{H}_{6} \mathrm{ClN}_{2} \mathrm{O}_{2} \mathrm{~S}^{+}, 225\right.\right.$ $\left[\mathrm{C}_{9} \mathrm{H}_{6} \mathrm{ClN}_{2} \mathrm{OS}\right]^{+}, 212\left[\mathrm{C}_{8} \mathrm{H}_{5} \mathrm{ClN}_{2} \mathrm{OS}\right]^{+}, 207\left[\mathrm{C}_{10} \mathrm{H}_{11} \mathrm{~N}_{2} \mathrm{O}_{3}\right]^{+}, 179\left[\mathrm{C}_{9} \mathrm{H}_{11} \mathrm{~N}_{2} \mathrm{O}_{2}\right]^{+}$, $179\left[\mathrm{C}_{8} \mathrm{H}_{4} \mathrm{ClN}_{2} \mathrm{O}\right]^{+}, 151\left[\mathrm{C}_{9} \mathrm{H}_{11} \mathrm{O}_{2}\right]^{+}, 153\left[\mathrm{C}_{7} \mathrm{H}_{4} \mathrm{ClNO}^{+}, 139\left[\mathrm{C}_{7} \mathrm{H}_{4} \mathrm{ClO}\right]^{+}, 137\right.$ $\left[\mathrm{C}_{7} \mathrm{H} \mathrm{ClN}_{4}\right]^{+}, 111\left[\mathrm{C} \mathrm{H} \mathrm{HCl}^{+}, 85\left[\mathrm{C}_{4} \mathrm{H}_{2} \mathrm{Cl}\right]^{+}, 51\left[\mathrm{C}_{4} \mathrm{H}_{3}\right]^{+}\right.$

2.9.7. $\quad N^{\prime}$-(2,4-Dimethoxybenzylidene)-2-(5-(2-chlorophenyl)-1,3,4Oxadiazol-2-ylthio)acetohydrazide (11g)

White amorphous solid; Yield: $81 \%$; M.P.: $162-164{ }^{\circ} \mathrm{C}$; Molecular Formula: $\mathrm{C}_{19} \mathrm{H}_{17} \mathrm{ClN}_{4} \mathrm{O}_{4} \mathrm{~S}$; Molecular Weight: $432 \mathrm{gmol}^{-1}$; IR $\left(\mathrm{KBr}, v_{m} / \mathrm{cm}^{-1}\right)$ :
3067 (Ar C-H), $1648(\mathrm{C}=\mathrm{N}), 1607(\mathrm{Ar} \mathrm{C}=\mathrm{C}), 1246$ (C-O-C), $698(\mathrm{C}-\mathrm{Cl}), 616$ (C-S); ${ }^{1} \mathrm{H}-\mathrm{NMR}(600 \mathrm{MHz}, \mathrm{DMSO}-d, \delta / \mathrm{ppm}): 11.63$ (s, $\left.1 \mathrm{H}, \mathrm{CONH}\right), 8.29$ (s, $1 \mathrm{H}, \mathrm{H}-7$ '"), 7.91 (d, $J=7.8 \mathrm{~Hz}, 1 \mathrm{H}, \mathrm{H}-6$ '), 7.74 (d, $J=8.4 \mathrm{~Hz}, 1 \mathrm{H}, \mathrm{H}-6$ "'), $7.63\left(\mathrm{~d}, J=7.2 \mathrm{~Hz}, 1 \mathrm{H}, \mathrm{H}-3^{\prime}\right), 7.44\left(\mathrm{t}, J=7.8 \mathrm{~Hz}, 1 \mathrm{H}, \mathrm{H}-5^{\prime}\right), 7.39$ (t, $J=8.4$ $\mathrm{Hz}, 1 \mathrm{H}, \mathrm{H}-4$ '), 6.62 (d, $J=2.4 \mathrm{~Hz}, 1 \mathrm{H}, \mathrm{H}-3$ '”'), 6.56 (dd, $J=7.8,2.4 \mathrm{~Hz}, 1 \mathrm{H}$, H-5"'), 4.63 (s, 2H, H-2"), 3.81 (s, 3H, CH O-2"'), 3.81 (s, 3H, $\mathrm{CH}_{3} \mathrm{O}-4$ "'); EIMS (m/z): $434[\mathrm{M}+2]^{+}, 432[\mathrm{M}]^{+}, 253\left[\mathrm{C}_{10} \mathrm{H}_{6} \mathrm{ClN}_{2} \mathrm{O}_{2} \mathrm{~S}^{+}, 225\left[\mathrm{C}_{9} \mathrm{H}_{6} \mathrm{ClN}_{2} \mathrm{OS}\right]^{+}\right.$, $212\left[\mathrm{C}_{8} \mathrm{H}_{5} \mathrm{ClN}_{2} \mathrm{OS}\right]^{+}, 207\left[\mathrm{C}_{10} \mathrm{H}_{11} \mathrm{~N}_{2} \mathrm{O}_{3}\right]^{+}, 179\left[\mathrm{C}_{9} \mathrm{H}_{11} \mathrm{~N}_{2} \mathrm{O}_{2}\right]^{+}, 179\left[\mathrm{C}_{8} \mathrm{H}_{4} \mathrm{ClN}_{2} \mathrm{O}\right]^{+}$, $151\left[\mathrm{C}_{9} \mathrm{H}_{11} \mathrm{O}_{2}\right]^{+}, 153\left[\mathrm{C}_{7} \mathrm{H}_{4} \mathrm{ClNO}\right]^{+}, 139\left[\mathrm{C}_{7} \mathrm{H}_{4} \mathrm{ClO}\right]^{+}, 137\left[\mathrm{C}_{7} \mathrm{H}_{4} \mathrm{ClN}\right]^{+}, 111$ $\left[\mathrm{C}_{6} \mathrm{H}_{4} \mathrm{Cl}\right]^{+}, 85\left[\mathrm{C}_{4} \mathrm{H}_{2} \mathrm{Cl}\right]^{+}, 51\left[\mathrm{C}_{4} \mathrm{H}_{3}\right]^{+}$

2.9.8. $\quad N$ '-(2,5-Dimethoxybenzylidene)-2-(5-(2-chlorophenyl)-1,3,4oxadiazol-2-ylthio)acetohydrazide (11h)

White amorphous solid; Yield: $85 \%$; M.P.: $170-172{ }^{\circ} \mathrm{C}$; Molecular Formula: $\mathrm{C}_{19} \mathrm{H}_{17} \mathrm{ClN}_{4} \mathrm{O}_{4} \mathrm{~S}$; Molecular Weight: $432 \mathrm{gmol}^{-1}$; IR $\left(\mathrm{KBr}, v_{\max } / \mathrm{cm}^{-1}\right)$ : $3084(\mathrm{Ar} \mathrm{C}-\mathrm{H}), 1636(\mathrm{C}=\mathrm{N}), 1613(\mathrm{Ar} \mathrm{C}=\mathrm{C}), 1251(\mathrm{C}-\mathrm{O}-\mathrm{C}), 699(\mathrm{C}-\mathrm{Cl}), 623$ (C-S); ${ }^{1} \mathrm{H}-\mathrm{NMR}$ (600 MHz, DMSO- $\left.d_{6}, \delta / \mathrm{ppm}\right): 11.76(\mathrm{~s}, 1 \mathrm{H}, \mathrm{CONH}), 8.36$ (s, 1H, H-7'”), 7.93 (d, $\left.J=7.8 \mathrm{~Hz}, 1 \mathrm{H}, \mathrm{H}-6^{\prime}\right), 7.62\left(\mathrm{~d}, J=7.8 \mathrm{~Hz}, 1 \mathrm{H}, \mathrm{H}-3^{\prime}\right)$, 7.39 (d, $J=9.0 \mathrm{~Hz}, 1 \mathrm{H}, \mathrm{H}-4$ '”), $7.26(\mathrm{t}, J=7.2 \mathrm{~Hz}, 1 \mathrm{H}, \mathrm{H}-5$ '), 7.17 (t, $J=$ $\left.8.4 \mathrm{~Hz}, 1 \mathrm{H}, \mathrm{H}-4^{\prime}\right), 7.05$ (d, $\left.\left.J=7.8 \mathrm{~Hz}, 1 \mathrm{H}, \mathrm{H}-3^{\prime \prime}\right)^{\prime}\right), 6.97(\mathrm{~d}, J=3.6 \mathrm{~Hz}, 1 \mathrm{H}$, H-6"'), 4.64 (s, 2H, H-2"), 3.82 (s, 3H, CH O-5"'), 3.74 (s, 3H, CH O-2"'); EIMS (m/z): $434[\mathrm{M}+2]^{+}, 432[\mathrm{M}]^{+}, 253\left[\mathrm{C}_{10} \mathrm{H}_{6} \mathrm{ClN}_{2} \mathrm{O}_{2} \mathrm{~S}^{+}, 225\left[\mathrm{C}_{9} \mathrm{H}_{6} \mathrm{ClN}_{2} \mathrm{OS}\right]^{+}\right.$, $212\left[\mathrm{C}_{8} \mathrm{H}_{5} \mathrm{ClN}_{2} \mathrm{OS}\right]^{+}, 207\left[\mathrm{C}_{10} \mathrm{H}_{11} \mathrm{~N}_{2} \mathrm{O}_{3}\right]^{+}, 179\left[\mathrm{C}_{9} \mathrm{H}_{11} \mathrm{~N}_{2} \mathrm{O}_{3}\right]^{+}, 179\left[\mathrm{C}_{8} \mathrm{H}_{4} \mathrm{ClN}_{2} \mathrm{O}\right]^{+}$, $151\left[\mathrm{C}_{9} \mathrm{H}_{11} \mathrm{O}_{2}\right]^{+}, 153\left[\mathrm{C}_{7} \mathrm{H}_{4} \mathrm{ClNO}\right]^{+}, 139\left[\mathrm{C}_{7} \mathrm{H}_{4} \mathrm{ClO}\right]^{+}, 137\left[\mathrm{C}_{7} \mathrm{H}_{4} \mathrm{ClN}\right]^{+}, 111$ $\left[\mathrm{C}_{6} \mathrm{H} \mathrm{Cl}_{4}\right]^{+}, 85^{1}\left[\mathrm{C}_{4} \mathrm{H}_{2} \mathrm{Cl}^{+}, 51\left[\mathrm{C}_{4} \mathrm{H}_{3}\right]^{+}\right.$

2.9.9. $\quad N^{\prime}$-(3,4-Dimethoxybenzylidene)-2-(5-(2-chlorophenyl)-1,3,4oxadiazol-2-ylthio)acetohydrazide (11i)

White amorphous solid; Yield: $80 \%$; M.P.: $156-158{ }^{\circ} \mathrm{C}$; Molecular Formula: $\mathrm{C}_{19} \mathrm{H}_{17} \mathrm{ClN}_{4} \mathrm{O}_{4} \mathrm{~S}$; Molecular Weight: $432 \mathrm{gmol}^{-1}$; IR $\left(\mathrm{KBr}, v_{\text {mar }} / \mathrm{cm}^{-1}\right)$ : $3079(\mathrm{Ar} \mathrm{C}-\mathrm{H}), 1683(\mathrm{C}=\mathrm{N}), 1605(\mathrm{Ar} \mathrm{C}=\mathrm{C}), 1248(\mathrm{C}-\mathrm{O}-\mathrm{C}), 702(\mathrm{C}-\mathrm{Cl}), 631$ (C-S); ${ }^{1} \mathrm{H}-\mathrm{NMR}\left(600 \mathrm{MHz}\right.$, DMSO- $\left.d_{6}, \delta / \mathrm{ppm}\right): 11.73(\mathrm{~s}, 1 \mathrm{H}, \mathrm{CONH}), 8.16(\mathrm{~s}$, 1H, H-7'”), 7.93 (dd, $J=7.8,1.8 \mathrm{~Hz}, 1 \mathrm{H}, \mathrm{H}-6$ ') 7.59 (d, $J=7.8 \mathrm{~Hz}, 1 \mathrm{H}, \mathrm{H}-3^{\prime}$ ), $7.44\left(\mathrm{t}, J=7.8 \mathrm{~Hz}, 1 \mathrm{H}, \mathrm{H}-5^{\prime}\right), 7.38\left(\mathrm{t}, J=7.2 \mathrm{~Hz}, 1 \mathrm{H}, \mathrm{H}-4^{\prime}\right), 7.33$ (d, $J=1.8$ Hz, 1H, H-2"') 7.19 (dd, $J=8.4,1.8 \mathrm{~Hz}, 1 \mathrm{H}, \mathrm{H}-6$ "') 6.99 (d, $J=8.4 \mathrm{~Hz}, 1 \mathrm{H}$, H-5"'), 4.65 (s, 2H, H-2"), 3.82 (s, 3H, CH $\mathrm{O}-3$ "'), 3.80 (s, 3H, $\mathrm{CH}_{3} \mathrm{O}-4$ "');

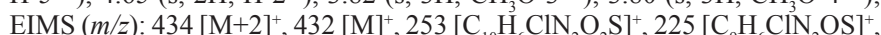
$212\left[\mathrm{C}_{8} \mathrm{H}_{5} \mathrm{ClN}_{2} \mathrm{OS}\right]^{+}, 207\left[\mathrm{C}_{10} \mathrm{H}_{11} \mathrm{~N}_{2} \mathrm{O}_{3}\right]^{+}, 179\left[\mathrm{C}_{9} \mathrm{H}_{11} \mathrm{~N}_{2} \mathrm{O}_{2}\right]^{+}, 179\left[\mathrm{C}_{8} \mathrm{H}_{4} \mathrm{ClN}_{2} \mathrm{O}\right]^{+}$, $151\left[\mathrm{C}_{9} \mathrm{H}_{11} \mathrm{O}_{2}\right]^{+}, 153\left[\mathrm{C}_{7} \mathrm{H}_{4} \mathrm{ClNO}\right]^{+}, 139\left[\mathrm{C}_{7} \mathrm{H}_{4} \mathrm{ClO}^{+}, 137 \mathrm{C}_{7} \mathrm{H}_{4} \mathrm{ClN}\right]^{+}, 111$ $\left[\mathrm{C}_{6} \mathrm{H}_{4} \mathrm{Cl}\right]^{+}, 85\left[\mathrm{C}_{4} \mathrm{H}_{2} \mathrm{Cl}\right]^{+}, 51\left[\mathrm{C}_{4} \mathrm{H}_{3}\right]^{+}$

\subsection{Antibacterial activity assay}

The antibacterial activity of all the synthesized molecules was analyzed by using the reported method ${ }^{19-21}$ after slight modifications.

2.11. Enzyme inhibition activity assay

The enzyme inhibition activity of all the synthesized molecules was analyzed against lipoxygenase enzyme, playing a key role in inflammatory diseases, by using the reported method ${ }^{14,15}$ but with slight modifications.

2.12 . Statistical analysis

The statistical analysis was performed after triplicate experiments on Microsoft Excel 2010 and the results were presented as mean \pm SEM.

\section{RESULTS AND DISCUSSION}

The acetamide and azomethine derivatives bearing 1,3,4-Oxadiazole nucleus, 7a-f and 11a-i respectively, have been inaugurated to analyze their antibacterial activity using certain bacterial strains of Gram bacteria (positive and negative) and enzyme inhibition activity against lipoxygenase enzyme. The procedures of all the reaction steps with appropriate conditions and spectral characterization have been illustrated in the experimental section. The compounds of series 7a-f exhibited better potential against the bacterial strains taken into account and the lipoxygenase enzyme but that of series 11a-i executed weak behavior.

\subsection{Chemistry}

The synthesis of molecules having 1,3,4-Oxadiazoles attached with amides or azomethine groups includes the conversion of 2-chlorobenzoic acid (1) to ethyl 2-chlorobenzoate (2), 2-chlorobenzohydrazide (3) and 5-(2-chlorophenyl)-1,3,4-Oxadiazol-2-thiol (4). A series of electrophiles, 6a-f, was prepared from aryl/alkyl amines, $\mathbf{5 a - f}$, by the reaction with 2-bromoacetyl bromide. The molecule $\mathbf{4}$ was set to react with $\mathbf{6 a - f}$ to yield $\mathbf{7 a - f}$ in one route. In another route, 4 was converted to ethyl 2-(5-(2-chlorophenyl)-1,3,4-Oxadiazol2-ylthio)acetate (8) by reaction with ethyl bromoacetate, 2-(5-(2-chlorophenyl)1,3,4-Oxadiazol-2-ylthio)acetohydrazide (9) by reaction with hydrated hydrazine and finally $11 \mathrm{a}-\mathbf{i}$ by the reaction of $\mathbf{9}$ with aryl carboxaldehydes, 10a-i. The whole synthesis is discussed with detail in the experimental section.

The compound $7 \mathbf{a}$ of first series showed $[\mathrm{M}+2]^{+}$and $[\mathrm{M}]^{+}$peaks at $\mathrm{m} / \mathrm{z}$ 
405 \& 403 respectively in the EIMS spectrum, and the other two distinct peaks resonating at $\mathrm{m} / \mathrm{z} 226$ and 151 were attributed to 5-(2-chlorophenyl)2-(methylthio)-1,3,4-Oxadiazole and 2-(methoxycarbonyl)aniline cationic fragments respectively. The mass fragmentation pattern of $7 \mathbf{a}$ has been elaborated in Figure-1. In IR spectrum, characteristic stretching absorption bands appearing at $v \quad\left(\mathrm{~cm}^{-1}\right) 3373(\mathrm{~N}-\mathrm{H}), 3092(\mathrm{C}-\mathrm{H}), 1675(\mathrm{C}=\mathrm{N}), 1647$ $(\mathrm{C}=\mathrm{O}), 1583(\mathrm{C}=\mathrm{C}), 1297$ (C-O-C) and 639 (C-S) confirmed the whole structure especially the 1,3,4-Oxadiazole ring and acetamoyl group in the molecule. In ${ }^{1} \mathrm{H}-\mathrm{NMR}$ spectrum chemical shift values of all protons were seen according to the expectations. In the aromatic region of ${ }^{1} \mathrm{H}-\mathrm{NMR}$ spectrum, the signals resonating at $\delta 7.91(\mathrm{dd}, J=8.0,1.6 \mathrm{~Hz}, 1 \mathrm{H}, \mathrm{H}-6$ ') $7.53(\mathrm{~d}, J=$ $\left.7.6 \mathrm{~Hz}, 1 \mathrm{H}, \mathrm{H}-3^{\prime}\right), 7.45$ (dt, $\left.J=7.6,1.2 \mathrm{~Hz}, 1 \mathrm{H}, \mathrm{H}-5^{\prime}\right)$ and 7.38 (dt, $J=8.0$, $0.8 \mathrm{~Hz}, 1 \mathrm{H}, \mathrm{H}-4$ ') were assigned to the chloro-substituted phenyl ring. The signals appearing at $\delta 8.64(\mathrm{~d}, J=8.4 \mathrm{~Hz}, 1 \mathrm{H}, \mathrm{H}-6$ "'), 8.01 (dd, $J=8.0,1.2$ $\mathrm{Hz}, 1 \mathrm{H}, \mathrm{H}-3$ '"'), 7.52 (t, $J=7.6 \mathrm{~Hz}, 1 \mathrm{H}, \mathrm{H}-5$ '") and 7.10 (t, $J=7.6 \mathrm{~Hz}, 1 \mathrm{H}$,
H-4"') were assigned to the di-substituted aromatic ring attached to nitrogen of acetamoyl group. In the aliphatic region of ${ }^{1} \mathrm{H}-\mathrm{NMR}$ spectrum, signals appearing at $\delta 4.22\left(\mathrm{~s}, 2 \mathrm{H}, \mathrm{CH}_{2}-2 "\right)$ and $3.86\left(\mathrm{~s}, 3 \mathrm{H}, \mathrm{CH}_{3} \mathrm{OCO}-2\right.$ "”) were assigned to two methylene protons and three protons of methoxy group in the molecule. The proton attached to heteroatom of acetamoyl group appeared as singlet at $\delta 11.60 \mathrm{ppm}$. On the basis of above structural analysis, the structure of 7a was assigned as 2-((5-(2-chlorophenyl)-1,3,4-Oxadiazol-2-yl)sulfanyl)$\mathrm{N}$-(2-(methoxycarbonyl)phenyl)acetamide. The compound 11a of second series presented the same splitting pattern for protons of 2-chlorophenyl group, methylene group and carbamoyl group. The signals resonating for the 2-nitrophenyl ring were $\delta(\mathrm{ppm}) 8.42$ (s, $1 \mathrm{H}, \mathrm{H}-7$ '"'), 8.00 (d, $J=7.8 \mathrm{~Hz}, 1 \mathrm{H}$, H-6"'), 7.91 (d, $J=7.8 \mathrm{~Hz}, 1 \mathrm{H}, \mathrm{H}-3$ "') and 7.60-7.56 (m, 2H, H-4" \& H-5"'). The characteristic absorption bands in IR spectrum and originating peaks in EIMS spectrum have been elucidated in experimental section.

Table-1: Different aryl/alkyl substituents.

\begin{tabular}{|c|c|c|c|c|c|c|c|}
\hline Com. & $\mathbf{R}$ & Com. & $\mathbf{R}$ & Com. & $\mathbf{R}$ & Com. & $\mathbf{R}$ \\
\hline $7 a$ & & $7 e$ & & $11 \mathrm{c}$ & & $11 \mathrm{~g}$ & \\
\hline $7 b$ & & $7 \mathrm{f}$ & & $11 \mathrm{~d}$ & & $11 \mathrm{~h}$ & \\
\hline $7 c$ & & $11 \mathrm{a}$ & & $11 \mathrm{e}$ & & $11 \mathrm{i}$ & \\
\hline $7 d$ & & 11b & & $11 f$ & & & \\
\hline
\end{tabular}

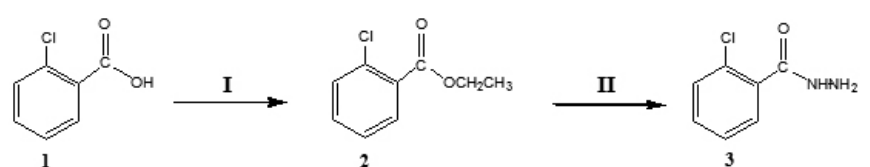<smiles>[R]C=NNC(=O)[CH]Sc1nnc(-c2ccccc2Cl)o1</smiles><smiles>Sc1nnc(-c2ccccc2Cl)o1</smiles>
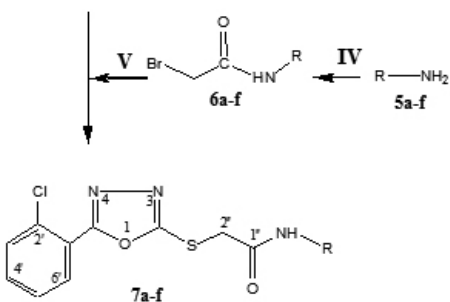

Scheme-1: Outline for synthesis of acetamide and azomethine derivatives (7a-f \& 11a-i). Reagents and conditions: (I) $\mathrm{EtOH} / \mathrm{H}_{2} \mathrm{SO}_{4}$, refluxing for 4-5 hours (II) $80 \% \mathrm{~N}_{2} \mathrm{H}_{4} \cdot \mathrm{H}_{2} \mathrm{O} / \mathrm{MeOH}$, stirring for 3-4 hours (III) $\mathrm{CS}_{2} / \mathrm{KOH} / \mathrm{EtOH}$, refluxing for 5-6 hours (IV) $\mathrm{BrCH}_{2} \mathrm{COBr} / \mathrm{Na}_{2} \mathrm{CO}_{3} / \mathrm{H}_{2} \mathrm{O}$, stirring for 1 hour (V) $\mathrm{NaH} / \mathrm{DMF}$, stirring for 4-5 hours (VI) $\mathrm{BrCH}_{2} \mathrm{COOC}_{2} \mathrm{H}_{5} / \mathrm{NaH} / \mathrm{DMF}$, stirring for 4-5 hours (VII) $80 \% \mathrm{~N}_{2} \mathrm{H}_{4} \cdot \mathrm{H}_{2} \mathrm{O} / \mathrm{MeOH}$, stirring for $3-4$ hours (VIII) $\mathrm{R}_{1} \mathrm{CHO}$ / $\mathrm{MeOH}$, stirring for 2-3 hours.

\subsection{Biological activities}

\subsubsection{Antibacterial activity (in vitro)}

The antibacterial activity was investigated against certain bacterial strains of gram-negative and gram-positive bacteria and the results have been shown as \%age inhibition and MIC (Minimum Inhibitory Concentration) value in Table- 2 and Table- 3 respectively. Initially synthesized acetamoyl molecules by our group were tested for their enzyme inhibition activity ${ }^{14-16}$ and now newly synthesized were tested for their antibacterial activity along with enzyme inhibition. All the compounds were tested for their activity against three gramnegative ( $S$. typhi, E. coli and P. aeroginosa) and two gram-positive bacteria (B. subtilis and $S$. aureus) by using broth dilution method taking ciprofloxacin as reference standard. The compounds of series 7a-f bearing acetamoyl group executed better inhibition activity against all the strains and that of series 11a-i remained weakly moderate. The compound $\mathbf{7 c}$ was the most better with significant MIC values and comparable to that of reference in the most of cases. It presented MIC values $\left(\mu \mathrm{gmL}^{-1}\right)$ of $9.11 \pm 0.54,9.67 \pm 0.39 \& 9.34 \pm 2.57$ relative to $8.22 \pm 1.62,9.02 \pm 1.84 \& 9.32 \pm 1.65$ against $S$. typhi, B. subtilis \& $S$. aureus respectively. The better activity of this molecule might be because of metasubstituted methylphenyl ring attached to nitrogen of acetamoyl group. S. typhi was actively inhibited by all the compounds of series $\mathbf{7 a - f}$ and also comparable to ciprofloxacin, the reference. Against $E$. coli, only 7 e remained inactive at all. The only compound $\mathbf{1 1 g}$ bearing 2,4-dimethoxyphenyl group showed significant inhibition potential against $S$. typhi with MIC value of $10.23 \pm 2.43$ $\mu \mathrm{gmL}^{-1}$. As evident from Table-3, the series $\mathbf{7 a - f}$ exhibited promising activity because small size and acetamoyl group but the series 11a-i remained inactive that might be because of increased size but with a few exceptions. The similar analogues of acetohydrazides were also synthesized for the 4-chlorophenyl group in place of 2-chlorophenyl group and found them moderate inhibitors ${ }^{22}$. The variation of chloro group from $4^{\text {th }}$ to $2^{\text {nd }}$ group resulted into comparatively low antibacterial activity and many remained inactive. 


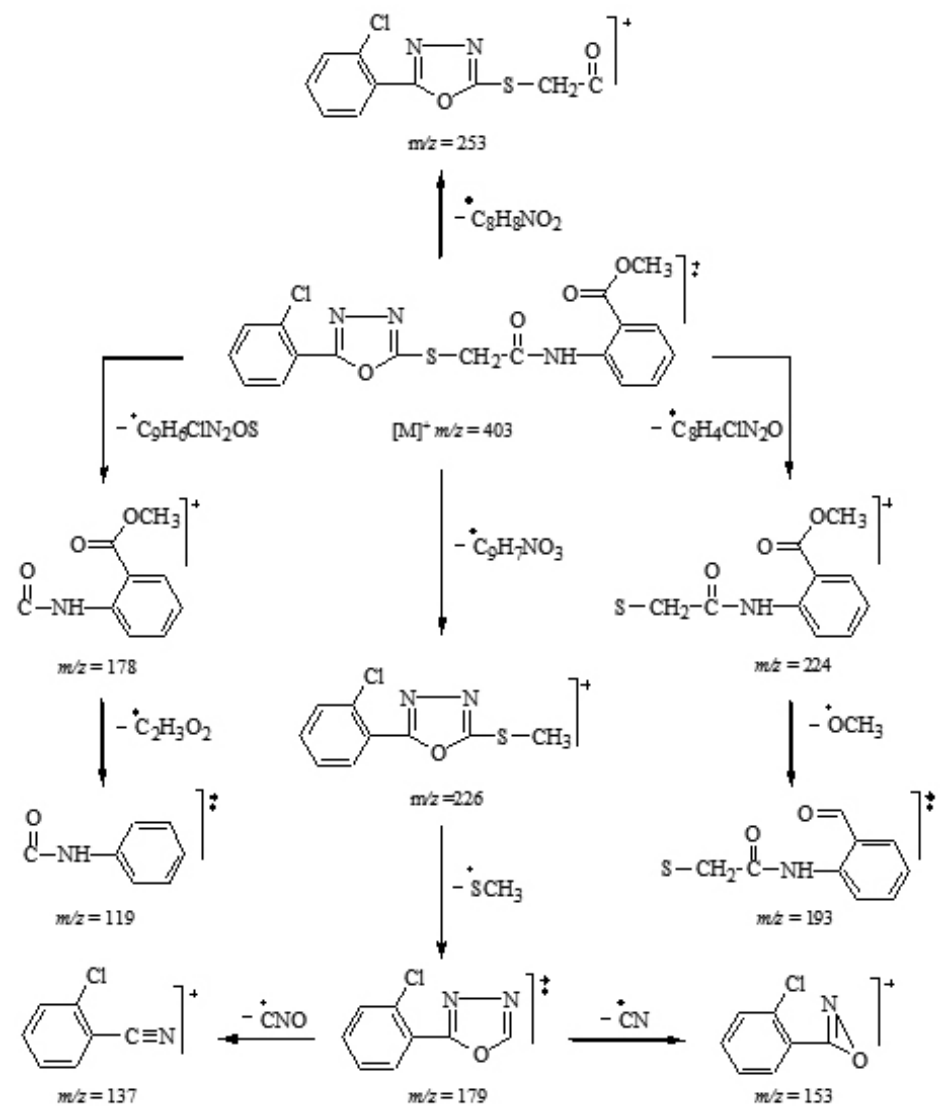

Figure-1: Mass fragmentation pattern of 2-((5-(2-Chlorophenyl)-1,3,4Oxadiazol-2-yl)sulfanyl)- $N$-(2-(methoxycarbonyl)phenyl)acetamide (7a).

Table-2: The \%age inhibition of antimicrobial activity of the synthesized compounds

\begin{tabular}{|c|c|c|c|c|c|}
\hline \multirow{2}{*}{ Compound } & \multicolumn{5}{|c|}{ \%age Inhibition } \\
\cline { 2 - 6 } & \multicolumn{2}{|c|}{ Gram negative bacteria } & \multicolumn{2}{c|}{ Gram positive bacteria } \\
\cline { 2 - 6 } & S. typhi & E. coli & $\begin{array}{c}\text { P. } \\
\text { aeroginosa }\end{array}$ & B. subtilis & S. aureus \\
\hline 7a & $79.21 \pm 0.96$ & $59.70 \pm 1.20$ & $72.61 \pm 1.62$ & $60.73 \pm 2.64$ & $68.93 \pm 3.05$ \\
\hline 7b & $78.17 \pm 2.33$ & $60.70 \pm 1.05$ & $69.93 \pm 2.71$ & $61.05 \pm 1.23$ & $72.45 \pm 0.31$ \\
\hline 7c & $62.46 \pm 0.46$ & $46.05 \pm 2.40$ & $60.19 \pm 1.51$ & $54.36 \pm 3.09$ & $53.67 \pm 2.02$ \\
\hline 7d & $63.34 \pm 2.61$ & $59.00 \pm 1.00$ & $67.72 \pm 1.88$ & $61.18 \pm 0.99$ & $67.14 \pm 0.05$ \\
\hline 7e & $68.83 \pm 3.17$ & $44.10 \pm 1.0$ & $66.72 \pm 3.87$ & $54.27 \pm 0.45$ & $55.66 \pm 0.26$ \\
\hline 7f & $73.92 \pm 0.75$ & $59.75 \pm 1.85$ & $70.04 \pm 2.86$ & $64.86 \pm 1.87$ & $66.02 \pm 0.31$ \\
\hline 11a & $69.17 \pm 4.58$ & $57.17 \pm 1.08$ & $40.65 \pm 1.35$ & $48.09 \pm 2.55$ & $68.13 \pm 5.00$ \\
\hline 11b & $59.06 \pm 5.00$ & $59.88 \pm 1.29$ & $61.40 \pm 5.00$ & $58.55 \pm 4.91$ & $42.20 \pm 4.76$ \\
\hline 11c & $49.48 \pm 5.00$ & $40.00 \pm 5.00$ & $12.15 \pm 5.00$ & $57.32 \pm 3.68$ & $37.20 \pm 5.00$ \\
\hline 11d & $42.71 \pm 0.52$ & $46.25 \pm 1.83$ & $35.10 \pm 3.70$ & $27.86 \pm 2.41$ & $44.40 \pm 2.64$ \\
\hline 11e & $56.77 \pm 0.31$ & $52.63 \pm 2.79$ & $46.50 \pm 5.00$ & $53.00 \pm 2.36$ & $53.63 \pm 5.00$ \\
\hline 11f & $52.40 \pm 1.25$ & $49.33 \pm 0.75$ & $33.40 \pm 0.30$ & $61.73 \pm 5.00$ & $51.10 \pm 4.95$ \\
\hline 11g & $71.04 \pm 1.46$ & $63.92 \pm 1.42$ & $52.75 \pm 0.45$ & $37.41 \pm 2.23$ & $47.42 \pm 0.71$ \\
\hline 11h & $65.94 \pm 4.48$ & $57.25 \pm 5.00$ & $47.70 \pm 2.50$ & $65.77 \pm 3.95$ & $51.10 \pm 4.95$ \\
\hline 11i & $53.59 \pm 3.59$ & $64.04 \pm 5.00$ & $50.05 \pm 1.25$ & $51.36 \pm 2.18$ & $51.15 \pm 0.60$ \\
\hline Ciprofloxacin & $\mathbf{9 0 . 4 2} \pm \mathbf{0 . 9 2}$ & $\mathbf{9 0 . 9 9} \pm \mathbf{0 . 1 5}$ & $\mathbf{9 1 . 9 4} \pm \mathbf{0 . 8 6}$ & $\mathbf{9 1 . 0 5} \pm \mathbf{1 . 1 8}$ & $\mathbf{9 1 . 1 1} \pm \mathbf{0 . 2 6}$ \\
\hline
\end{tabular}


Table-3: The MIC values of antimicrobial activity of the synthesized compounds.

\begin{tabular}{|c|c|c|c|c|c|}
\hline \multirow{3}{*}{ Compound } & \multicolumn{5}{|c|}{ MIC $(\mu \mathrm{g} / \mathrm{mL})$} \\
\hline & \multicolumn{3}{|c|}{ Gram negative bacteria } & \multicolumn{2}{|c|}{ Gram positive bacteria } \\
\hline & S. typhi & E. coli & P. aeroginosa & B. subtilis & S. aureus \\
\hline $7 \mathbf{a}$ & $9.17 \pm 0.38$ & $14.01 \pm 3.57$ & $10.86 \pm 0.75$ & $13.76 \pm 2.89$ & $15.06 \pm 1.07$ \\
\hline $7 b$ & $9.26 \pm 0.98$ & $14.53 \pm 1.50$ & $12.87 \pm 2.61$ & $13.31 \pm 0.61$ & $10.59 \pm 1.54$ \\
\hline $7 \mathrm{c}$ & $9.11 \pm 0.54$ & $11.72 \pm 0.71$ & $11.86 \pm 1.76$ & $9.67 \pm 0.39$ & $9.34 \pm 2.57$ \\
\hline $7 d$ & $10.44 \pm 1.54$ & $15.77 \pm 2.29$ & $12.88 \pm 3.12$ & $14.93 \pm 1.88$ & $11.21 \pm 0.65$ \\
\hline $7 e$ & $11.05 \pm 2.07$ & - & $12.76 \pm 1.31$ & $17.22 \pm 1.28$ & $17.12 \pm 1.43$ \\
\hline $7 f$ & $9.70 \pm 0.71$ & $15.93 \pm 1.01$ & $12.48 \pm 1.87$ & $14.19 \pm 2.72$ & $9.98 \pm 0.21$ \\
\hline $11 \mathrm{a}$ & $13.68 \pm 1.00$ & $15.11 \pm 5.00$ & - & - & $13.32 \pm 2.00$ \\
\hline $11 b$ & $17.32 \pm 0.98$ & $14.09 \pm 2.65$ & $14.93 \pm 1.17$ & $17.53 \pm 1.88$ & - \\
\hline $11 \mathrm{c}$ & - & - & - & $17.65 \pm 1.65$ & - \\
\hline 11d & - & - & - & - & - \\
\hline $11 \mathrm{e}$ & $18.57 \pm 0.55$ & $18.91 \pm 1.64$ & - & $19.08 \pm 3.87$ & $14.52 \pm 2.50$ \\
\hline $11 f$ & $18.19 \pm 1.82$ & - & - & $16.60 \pm 2.12$ & - \\
\hline $11 \mathrm{~g}$ & $10.23 \pm 2.43$ & $11.04 \pm 1.17$ & $17.20 \pm 1.25$ & - & - \\
\hline $11 \mathrm{~h}$ & $14.87 \pm 1.72$ & $12.82 \pm 2.12$ & - & $12.29 \pm 1.65$ & - \\
\hline $11 \mathrm{i}$ & $17.55 \pm 0.54$ & $15.41 \pm 5.00$ & $19.93 \pm 1.08$ & $18.05 \pm 0.87$ & $19.11 \pm 0.44$ \\
\hline Ciprofloxacin & $8.22 \pm 1.62$ & $8.87 \pm 2.00$ & $8.90 \pm 2.50$ & $9.02 \pm 1.84$ & $9.32 \pm 1.65$ \\
\hline
\end{tabular}

NOTE: Minimum inhibitory concentration (MIC) was measured with suitable dilutions (5-30 $\mu \mathrm{g} / \mathrm{well})$ and results were calculated using EZ-Fit Perrella Scientific Inc. Amherst USA software.

\subsubsection{Enzyme inhibition activity (in vitro)}

Because of action of lipoxygenase enzyme in inflammatory diseases ${ }^{14,15}$, the molecules were subjected to inhibition analysis of this enzyme and the results were obtained as \%age inhibition and $\mathrm{IC}_{50}$ (concentration for $50 \%$ inhibition) values taking Baicalein as reference standard, Table-4. Again the series 7a-f remained proficient and series 11a-i, the least active or inactive at all. The molecule $7 \mathbf{b}$ was the most active one with $\mathrm{IC}_{50}$ value of $69.9 \pm 0.87 \mu \mathrm{molL}^{-1}$ relative to reference with that of $22.4 \pm 1.3 \mu \mathrm{molL}^{-1}$. The molecules $7 \mathbf{d}$ and $7 \mathbf{e}$ remained inactive at all. This was inferred from the results that the substitution, position of substitution and size of molecule along with orientation played great role in binding ability to active site of an enzyme. Initially synthesized acetamoyl molecules by our group ${ }^{14-16}$ were tested for their enzyme inhibition activity and found relatively better inhibitors of lipoxygenase enzyme as compared to the presented molecules of both of the series.

\section{CONCLUSION}

The acetamoyl \& azomethine groups and 1,3,4-Oxadiazole ring have been known to possess valuable antibacterial and enzyme inhibition activities as referenced in the introduction section. The presented research work has shown that although these moieties are present in the molecules yet some other factors are to be considered to evaluate the biological activities such as the nature, size $\&$ position of substituent and also size of the whole molecule. The molecules of series 7a-f possessed acetamoyl group and 1,3,4-Oxadiazole ring but they all are of small size and so better antibacterial agents and lipoxygenase inhibitors. Comparatively the molecules of series 11a-i possessed azomethine group and 1,3,4-Oxadiazole ring but presented the moderate antibacterial and least enzyme inhibition activity because of their large size. The compounds of series 7a-f might be considerable for drug discovery program in pharmaceutical industries.

\section{ACKNOWLEDGEMENT}

The authors acknowledge the Higher Education Commission (HEC) of Pakistan for the financial assistance regarding spectral analysis of the synthesized molecules.
Table 4: The $\mathrm{IC}_{50}$ values of enzyme inhibition activity of the synthesized compounds

\begin{tabular}{|c|c|c|c|}
\hline \multirow{2}{*}{ Compound } & \multicolumn{3}{|c|}{ LOX } \\
\cline { 2 - 4 } & Conc. (mM) & Inhibition (\%) & IC $_{\mathbf{5 0}}\left(\boldsymbol{\mu \mathbf { m o l L } ^ { - 1 }}\right)$ \\
\hline 7a & 0.5 & $76.59 \pm 0.15$ & $170.5 \pm 0.89$ \\
\hline 7b & 0.25 & $79.39 \pm 0.63$ & $69.9 \pm 0.87$ \\
\hline 7c & 0.5 & $72.24 \pm 0.26$ & $271.6 \pm 1.34$ \\
\hline 7d & 0.5 & $58.59 \pm 0.15$ & $>500$ \\
\hline 7e & 0.5 & $49.33 \pm 0.65$ & - \\
\hline 7f & 0.5 & $69.53 \pm 0.56$ & $135.5 \pm 1.74$ \\
\hline 11a & 0.5 & $51.31 \pm 0.66$ & $>500$ \\
\hline 11b & 0.5 & $46.32 \pm 0.15$ & $>500$ \\
\hline 11c & 0.5 & $35.21 \pm 0.54$ & - \\
\hline 11d & 0.5 & $7.01 \pm 0.026$ & - \\
\hline 11e & 0.5 & $48.31 \pm 0.45$ & $>500$ \\
\hline 11f & 0.5 & $30.11 \pm 0.23$ & - \\
\hline 11g & 0.5 & $49.33 \pm 0.65$ & $>500$ \\
\hline 11h & 0.5 & $36.83 \pm 0.12$ & - \\
\hline 11i & 0.5 & $53.41 \pm 0.87$ & $>500$ \\
\hline Baicalein & $\mathbf{0 . 5}$ & $\mathbf{9 3 . 7 9} \pm \mathbf{1 . 2 7}$ & $\mathbf{2 2 . 4 \pm 1 . 3}$ \\
\hline
\end{tabular}

NOTE: $\mathrm{LOX}=$ Lipoxygenase enzyme. $\mathrm{IC}_{50}$ values (concentration for $50 \%$ inhibition) of compounds were recorded using EZ-Fit Enzyme kinetics software (Perella Scientific Inc. Amherst, USA).

\section{REFERENCES}

1. V.V. Dabholkar, N.V. Bhusari, Int. J. Environ. Pharm. Res. 4(1), 1, (2011) 
2. T.P. Mohan, B. Vishalakshi, K.S. Bhat, G.N. Kendappa, K.S. Rao, Indian J. Chem. 43B, 1798, (2004)

3. M. Rashid, A. Husain, R. Mishra, Eur. J. Med. Chem. 54, 855, (2012)

4. G. Sahin, E. Palaska, M. Ekizoglu, M. Ozalp, Il Farmaco 57, 539, (2002)

5. G. Autore, A. Caruso, S. Marzocco, B. Nicolaus, C. Palladino, A. Pinto, A. Popolo, M.S. Sinicropi, G. Tommonaro, C. Saturnino, Molecules 15, 2028, (2010)

6. G. Ayhan-Kılcıgil, S. Gurkan, T. Coban, E.D. Ozdamar, B. Can-Eke, Chem. Biol. Drug Des. 79, 869, (2012)

7. H. Jawed, S.U.A. Shah, S. Jamall, S.U. Simjee, Int. Immunopharmacol. $10,900,(2010)$

8. V. Kanagarajan, J. Thanusu, M. Gopalakrishnan, Eur. J. Med. Chem. 45, $1583,(2010)$

9. R. Sawant, D. Kawade, Acta. Pharm. 61, 353, (2011)

10. B.D. Narsibhai, D. Mishra, L.V. Vyavahare, A. Singh, Arch. Appl. Sci. Res. 4(4), 1816, (2012)

11. S. Rollas, S.G. Küçükgüzel, Molecules 12, 1910, (2007)

12. A.K. Shakya, Z. El-Agbar, Asian J. Chem. 20(4), 2515, (2008)

13. R.R. Somani, A.G. Agrawal, P.P. Kalantri, P.S. Gavarkar, E.D. Clercq, Int J. Drug Des. Discov. 2(1), 353, (2011)
14. Aziz-ur-Rehman, A. Fatima, N. Abbas, M.A. Abbasi, K.M. Khan, M. Ashraf, I. Ahmad, S.A. Ejaz, Pak. J. Pharm. Sci. 26(2), 345, (2013)

15. Aziz-ur-Rehman, A. Fatima, M.A. Abbasi, S. Rasool, A. Malik, M. Ashraf, I. Ahmad, S.A. Ejaz, J. Saudi Chem. Soc. doi: http://dx.doi.org/10.1016/j. jscs.2013.02.006, (2013)

16. S. Gul, Aziz-ur-Rehman, M.A. Abbasi, K. Nafeesa, A. Malik, M. Ashraf, T. Islmail, I. Ahmad, Asian J. Chem. 25(11), 6231, (2013)

17. H. Khalid, Aziz-ur-Rehman, M.A. Abbasi, A. Malik, S. Rasool, K. Nafeesa, I. Ahmad, S. Afzal, J. Saudi Chem. Soc. doi: http://dx.doi.org/10.1016/j. jscs.2013.05.001, (2013)

18. SciFinder: CAS Registry Number: $336173-64-9$

19. Aziz-ur-Rehman, K. Nafeesa, M.A. Abbasi, H. Kashfa, S. Rasool, I. Ahmad, S. Arshad, Pak. J. Chem. 3(2), 1, (2013)

20. M. Kaspady, V.K. Narayanaswamy, M. Raju, G.K. Rao, Lett. Drug Des. Discov. 6, 21, (2009)

21. C.R. Yang, Y. Zang, M.R. Jacob, S.I. Khan, Y.J. Zhang, X.C. Li, Antimicrob. Agents Ch. 50(5), 1710, (2006)

22. S. Rasool, Aziz-ur-Rehman, M.A. Abbasi, S. Gul, M.N. Akhtar, I. Ahmad, S. Afzal, Trop. J. Pharm. Res. 14(6), 1081, (2015). 